This document is a manuscript version of the following article:

Title: The distribution of crowding costs in public transport: New evidence from Paris

By: Haywood, Luke; Koning, Martin

Published in: Transportation Research Part A: Policy and Practice Volume 77, July 2015, Pages 182-201 Publisher: Elsevier | Year: 2010 DOI: 10.1016/j.tra.2015.04.005

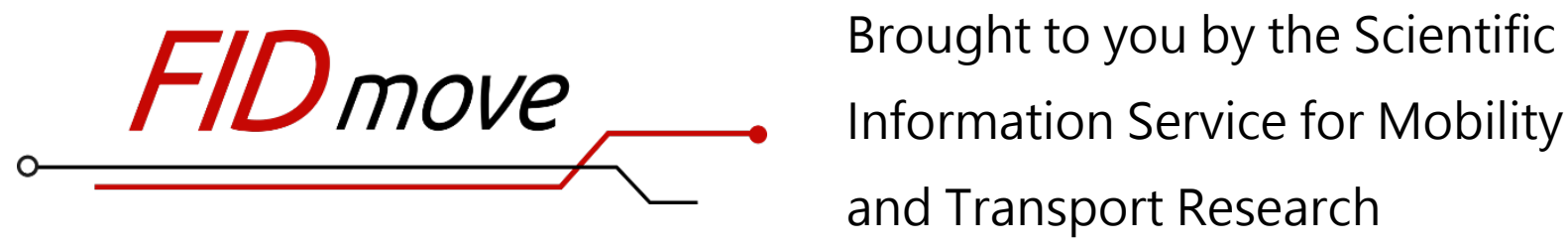

Fachinformationsdienst Mobilitäts- und Verkehrsforschung

Website: www.fid-move.de

Repository: publish.fid-move.de

Contact: publish@fid-move.de

(C) 2015. This manuscript version is made available under the CC-BYNC-ND 4.0 license.

http://creativecommons.org/licenses/by-nc-nd/4.0/ 


\title{
The Distribution of Crowding Costs in Public Transport: New Evidence from Paris
}

\author{
Luke Haywood*Martin Koning ${ }^{\dagger}$
}

7th February 2015

\begin{abstract}
Whilst congestion in automobile traffic increases trip durations, this is often not the case in rail-based public transport where congestion rather leads to in-vehicle crowding, often neglected in empirical stydies. Using original survey data from Paris, this article assesses the distribution of comfort costs of congestion in public transport. Estimating willingness to pay for less crowded trips at different levels of in-vehicle passenger density we cannot reject a simple linear relationship between crowding costs and density. We apply our results to the cost-benefit analysis of a recent Parisian public transport project.
\end{abstract}

Keywords: Evaluation of non-market goods, travel comfort, crowding costs, contingent valuation method, Paris subway

JEL Codes: D61, R41, L92

${ }^{*}$ DIW Berlin, Public Economics Department, Mohrenstr. 58, 10117 Berlin, Germany, $+49(0) 3089789$ 320, LHaywood@diw.de.

${ }^{\dagger}$ Université Paris Est, IFSTTAR-SPLOTT, Bvd Newton 14-20, Cité Descartes, 77447 Marne-la-Vallée, France, $+33(0) 18166$ 8780, martin.koning@ifsttar.fr. 


\section{Introduction}

From an economic perspective, good urban transport policy should make efficient use of the scarce ressources time and space, subject to public budget constraints. It has come to be accepted that past policies have led to inefficiently high automobile usage in many countries (Newman and Kenworthy (1989)). Transport policies have thus typically focussed on modal shift strategies: increasing the patronage of public transport (PT) systems, especially with the use of congestion or environmental tolls for cars (Lindsey (2006), Small and Verhoef (2007), Tsekeris and Voss (2009)) or subsidies for PT (Parry and Small (2009)). Nevertheless, not always were such policies accompanied by increased PT supply. Where supply elasticity is low - as is the case for most rail-based PT systems - density of passengers in PT systems will consequently increase.

The traditional view assumes that transport users' utility depends on time and money only. Under this perspective, as long as the saturation point of PT is not reached (Kraus and Yoshida (2002)), increasing PT usage should almost always lead to a societal gain. With more individuals sharing the fixed costs of PT provision, there will be economies of scale, such as a higher frequency of vehicles in the PT network (Mohring (1972), Proost and Dender (2008)). Reduced road congestion also decreases costs of automobile transits and environmental externalities (Parry et al. (2007), Malibach et al. (2008)). However, this ignores comfort costs of PT congestion occurring well before the network reaches a bottleneck. Considering that individuals care about the amount of space in vehicles, i.e. the inverse of passenger density ${ }^{1}$, crowded travel conditions may decrease their utilities even if travel time is kept constant. Therefore, there is no free lunch by decreasing the attractiveness of automobile transport without improving the supply of PT.

\footnotetext{
${ }^{1}$ We recognize that apart from passenger density, subjective factors may also play a role in perceived levels of crowding (see Cox et al. (2006) or Mohd Mahudin et al. (2012)). We here focus only on passenger density, thus using crowding and congestion interchangeably in what follows.
} 
Whereas some authors have integrated such capacity constraints in their theoretical analysis of PT supply and pricing rules (Jansson (1979), Kraus (1991)), empirical applications did not fully consider crowding costs until recently. Thus Parry and Small (2009) include crowding costs as a dimension of the two modes problem in their theoretical framework analyzing the optimal level of PT subsidies. However, they neglect them when calibrating their model empirically. Recently, research has looked at the effects of PT crowding on the choices among competing investments' projects (Tirachini et al. (2010)), on estimates of PT demand (Tirachini et al. (2013)), as well as on optimal PT pricing, service frequency and vehicle design (Tirachini et al. (2014)). Kilani et al. (2014) compare road and PT pricing in the Paris region during peaks in the presence of $\mathrm{PT}$ crowding. Some recent papers also include crowding cost as a component of individuals' route choices over railway systems (Pel et al. (2014), Kato et al. (2010), Leurent and Liu (2009), Raveau et al. (2011)). Empirical evidence on PT crowding has been gathered mainly in Britain and Australia, mainly by consulting firms on behalf of railways regulators (see Li and Hensher (2011) or Wardman and Whelan (2011)). ITF-OECD (2014) summarizes official crowding valuations used in developed countries for socioeconomic assessment of transport projects.

This article adds to this literature by examining the utility costs of PT congestion using contingent valuation methodology (CVM) on a survey collected late 2010 in the Paris subway. We use declared preferences on hypothetical states of nature in order to estimate the distribution of the marginal willingness to pay for less crowded travelling conditions. Importantly, we cannot reject a linear relationship between our measure of density and crowding costs. Moreover, we confirm the result of Tirachini et al. (2014) that PT crowding is a first-order urban externality that should be considered by policy makers.

The Paris area is a good case in point to investigate PT crowding costs. 
First, the Paris PT network is the most intensively used in Europe (UITP (2014)) and is confronted with chronic crowding issues. Over the last ten years, road space was reallocated from cars to cleaner transport modes (buses, streetcars, bikes). This popular policy of quantity regulation (Prud'homme and Kopp (2008)) has reduced the average speed of cars in Paris by $10 \%$ between 2000 and 2007 (Observatoire de la mobilité de la ville de Paris (2007)). Following the rise of travel costs for cars, individual motorised traffic with Paris as destination or origin has diminished by $24 \%$ (in passenger-km, pkm, see Kopp (2011)). Whilst usage of motorbikes and bicycles has increased, the majority of the modal switch occurred towards the PT network.

Table 1: Evolution of the Paris subway usage

\begin{tabular}{|c|c|c|c|c|}
\hline & $\begin{array}{c}\text { Demand } \\
(\mathrm{m} \text { pass-km })\end{array}$ & $\begin{array}{c}\text { Supply } \\
(\mathrm{m} \text { train-km })\end{array}$ & $\begin{array}{c}\text { Density } \\
\left(\mathrm{pass} / \mathrm{m}^{2}\right)\end{array}$ & $\begin{array}{c}\text { Regularity } \\
(\%)\end{array}$ \\
\hline 2000 & 6,011 & 42 & 1.0 & 98 \\
2009 & 7,353 & 48 & 1.1 & 98 \\
\hline
\end{tabular}

Sources: Syndicat des Transports de la Région Ile-de-France (2009), Observatoire de la mobilité de la ville de Paris (2000) and Observatoire de la mobilité de la ville de Paris (2009). For the density indicator we assume that a train has 557 places, $139 \mathrm{~m}^{2}$. The regularity indicator is defined as the share of travellers who wait less than 3 minutes during peak periods.

As illustrated in table (1), PT patronage in the Paris subway increased by $22 \%$ between 2000 and 2009 such that now $60 \%$ of all trips in Paris use rail-based PT (on at least part of the journey). Supply could not keep up with demand, leading to increased crowding: in-vehicle passenger density grew by $10 \%$ between 2000 and $2009^{2}$. Note that there is no indication that the Paris subway is at a bottleneck, where demand negatively affects regularity and travel time. Thus the share of users having to wait more than

\footnotetext{
${ }^{2}$ We have no data about the distribution over time of PT supply, thus we are unable to dis-aggregate the evolution of passenger density across peaks and off-peaks. However, we know that over 2001-2010 the subway demand increased faster during off-peaks $(+33 \%)$ that during peaks $(+13 \%)$, see OMNIL (2013). As a consequence, in-vehicle crowding has probably seen a slower increase during peaks than during off-peaks.
} 
3 minutes during peaks was constant over the period 2000-2009 (Observatoire de la mobilité de la ville de Paris (2000), Observatoire de la mobilité de la ville de Paris $(2009))^{3}$. As a result, we can focus our analysis on the comfort costs of PT crowding. Combined with growing road congestion, the deterioration of PT travel conditions has been quoted as an important factor affecting job quality in Paris (Technologia (2010), ORSTIF (2010)). Commuters' complaints also figure prominently in municipal and regional elections (2008, 2010 and 2014), stressing the relevance of our analysis.

In a recent research paper commissioned by the Parisian PT regulator, Kroes et al. (2013) consider crowding costs in different types of PT. Although their framework used to value crowding costs is similar to ours, our approach presents at least three differences. As opposed to many studies on that topic that are based on online or mail surveys (Kroes et al. (2013), Whelan and Crockett (2009)), we rely on a field survey held directly on subway platforms. Surveys based on personal interactions have been found to provide more reliable estimates ${ }^{4}$ and it allows to present hypothetical scenarios to PT users with respect to their current trip conditions, making answers more reliable (Hensher (2010)). Second, our contingent experiments (and corresponding estimates) are based on follow-up questions. As a consequence, we explicitly model the potential dependency of individuals' answers, often stressed by studies in environmental economics (Haab and McConnel (2003), Alberini et al. (1997), Flachaire and Hollard (2007)), but not always discussed in crowding valuation studies (Li and Hensher (2011)). Finally, we use the distribution of crowding values found to estimate a relationship between crowding costs and levels of in-vehicle passenger density that may be useful for policy analyses.

The rest of the paper is organized as follows. Section (2) presents the

\footnotetext{
${ }^{3}$ This refers only to the subway system in the centre of Paris (métro), not the regional system (RER).

${ }^{4}$ Szolnoki and Hoffman (2013) evaluate extensively the reliability of online, face-to-face and telephone surveys in consumer research.
} 
framework used to value PT crowding costs and reviews existing literature. Section (3) presents the survey design used to elicit preferences and summary statistics. Section (4) presents the empirical strategy and results, showing how increased density generates rising crowding costs. Using the distribution of crowding costs, section (5) proposes a function linking passenger density to congestion costs and discusses policy implications. As a topical example we show how taking into account PT crowding influences a cost-benefit analysis of the introduction of driverless trains in the Paris metro. Section (6) concludes.

\section{Valuing Crowding Costs}

In order to assess the welfare costs of PT crowding, we write the utility of PT user $i$ at congestion level $j\left(U_{i, j}\right)$ as a function of in-vehicle travel time $t_{i}$, monetary expenditures $p_{i}$ and an indicator function for the level of comfort $c_{j} \in\{0, \ldots, J\}$ where $J$ is the most comfortable (least crowded) condition. The two first arguments, money and time, determine the generalized cost of travels once time resources are valued at their opportunity cost $w_{i}$ for which we use a common opportunity cost in the empirical specification (see appendix (7.6) for an alternative specification).

We integrate comfort as a factor moderating the influence of trip duration. This is in line with the idea of comfort as a factor moderating flow utility, not a fixed utility cost. Different causes of discomfort may be associated with different types of nuisance, some of them independent of trip duration. In a separate module of this data, individuals were asked about their reasons for disliking crowded conditions. The most important cause of nuisance related to physical proximity per se, which we take to persist throughout trip duration, ahead of factors such as smell or risk of injury which may contain a stronger one-off fixed-cost element. Contrasting different functional forms, Whelan and Crockett (2009) also prefer the specification of comfort costs as 
time-dependent. The US Department of Transport also recommends such a specification (Belenky (2011)) as does (ITF-OECD (2014)). Finally, we allow individual characteristics $X_{i}$ to influence utility, which can thus be given as

$$
U_{i, j}=\alpha+\theta p_{i}+\sum_{j=0}^{J} c_{j} \beta_{j} t_{i}+\delta X_{i}+\varepsilon_{i}
$$

Consider two states of nature with $j=0$ for peak periods in which transport users must stand and $j=1$ for off-peak periods in which PT users are seated. The welfare difference due to travel comfort is then linked to the marginal disutilities of in-vehicle time $\left(\beta_{j}<0\right)^{5}$, such that if utility is higher in the less congested state we will find a difference in the associated values of $\beta$ : $U_{i, 1}-U_{i, 0}>0 \Rightarrow\left(\beta_{1}-\beta_{0}\right) t_{i}>0 \Rightarrow \beta_{1}>\beta_{0}$. Estimating the distribution of congestion costs requires a range of states $j$.

This formulation is consistent with a wide range of reasons for preferring less congested PT. Crowding reduces the probability of finding a seat and prevents individuals from using travel time for other activities (polychronic use of time). Congestion in PT may also induce security fears, increase noise levels and reduce hygiene (Li (2003), Litman (2008), CRCFRI (2012)). Low density is quoted as one of the main desirable attributes of PT (Cantwell et al. (2009), dell'Olio et al. (2011)). Finally, PT crowding can impact individuals' well-being, with indirect consequences found on stress, mortality, productivity losses and stated desire to quit a job (Wener et al. (2005), Evans and Wener (2007), Cox et al. (2006), Mohd Mahudin et al. (2012), Tirachini et al. (2014)).

\footnotetext{
${ }^{5}$ Section (4) tests whether individual characteristics may also influence the appreciation of comfort.
} 


\subsection{Finding the equivalent variation}

Comfortable travel conditions constitute a non-market good which is not directly priced. Two strategies can be taken to reveal its implicit value (Haab and McConnel (2003), Mitchell and Carson (1989)): First, observed behaviors can be used to infer hedonic prices and transport costs as revealed preferences. This requires a setting where choices between differentially congested PT systems are observed. In absence of such a setting, second, stated preferences about hypothetical scenarios can be used. The basic idea of CVM is to find the equivalent variation in economic resources which makes individuals indifferent between states with different levels of the non-market good $\left(U_{i, 1}=U_{i, 0}\right)$. This method has been used extensively by environmental economists, but also in the valuation of transport externalities and to assess the subjective cost of travel time (Wardman (2001)).

For reasons outlined below (see section (3.1)), our survey proposes scenarios in terms of longer commuting time (rather than financial cost) in exchange for less congested PT. Starting from the indifference condition, the proposed trade-off between travel time and comfort then allows us to study two types of equivalent variation:

First, willingness to travel longer $(W T T L)$ is the additional travel time in the less congested state which would leave individuals indifferent with the more congested state:

$$
\begin{aligned}
U_{i, 1} & =U_{i, 0} \\
\beta_{0} t_{i} & =\beta_{1}\left(t_{i}+W T T L\right) \\
W T T L & =t_{i} \frac{\left(\beta_{0}-\beta_{1}\right)}{\beta_{1}}
\end{aligned}
$$

Second, the equivalent variation can also be expressed as a change in the marginal disutility of travel time $\beta_{j}$, a "time multiplier" with $T m \equiv$ $\frac{\beta_{0}}{\beta_{1}}>1$. Tm corresponds to the ratio of the marginal disutilities between 
congested and non-congested states, i.e. a marginal rate of substitution between comfortable and uncomfortable travel times. The two concepts are closely linked:

$$
W T T L=t_{i}(T m-1)
$$

To value crowding costs in monetary terms, i.e. derive the willingness to pay $(W T P)$, we can apply a time opportunity cost $w_{i}$ to $W T T L$ and $T m$ expressed in minutes ${ }^{6}$. PT congestion costs are then expressed in $€ /$ trip and $€$ /hour respectively. Above all, we can introduce $W T T L$ and Tm into the generalized cost function of PT usage. Section (5) shows how this can be used for policy analysis.

Before considering the empirical evidence on PT crowding, note that the initial trade-off between travel time and comfort proposed to PT users can be expanded with follow-up questions depending on individuals' answers (see section (3)). This introduces interdependency of responses (and, with it, econometric challenges), but improves the precision of $\beta_{j}$ estimates (Hanemann et al. (1991)).

\subsection{Crowding cost distributions}

Studies using CVM to appraise PT crowding costs have focussed mainly on a small number of countries - Li and Hensher (2011), Wardman and Whelan (2011) and ITF-OECD (2014) provide recent reviews ${ }^{7}$. Valuations in terms of $T m$ are generally preferred since they are more easily comparable across PT service types and places. In their meta-analysis of 17 British studies,

\footnotetext{
${ }^{6}$ Formally, the time opportunity cost corresponds to the ratio between the marginal utilities of time (in the benchmark situation of no crowding) and money, i.e. $w_{i}=\frac{\beta_{1}}{\theta}$. Because our contingent scenarios do not allow us to estimate $\theta$, we use a function of individuals' income to calibrate the time opportunity cost as well as a common time opportunity cost, see the discussion in section (4) and appendix (7.6).

${ }^{7} \mathrm{Li}$ and Hensher (2011) focuse on Australia and also provide evidence from the US and Israel. ITF-OECD (2014) presents official crowding values for Japan, New-Zealand, France and Sweden. Basu and Hunt (2012) present evidence for India.
} 
Wardman and Whelan (2011) highlight large variation in crowding costs across cities and PT modes. They find an average Tm of 1.19 for seated trips and of 2.32 for standing journeys. Values can become much larger for load factors exceeding 150-200\% ${ }^{8}$. Li and Hensher (2011) report average Tm of 1.34-2.00 for the Australian PT network. PT crowding costs are also influenced by in-vehicle travel time and trip motives (with higher valuations for non-commuting) ${ }^{9}$.

Until recently, few studies on PT crowding costs have been conducted in France. Debrincat et al. (2006) consider crowding as a component of the welfare impact of trains' reliability in the Greater Paris region. Their survey combines different waiting times, levels of information for users and comfort situations (seat, stand, stand in crowded conditions). They find that the discomfort generated by standing during the trip corresponds to a WTTL of 5-20 minutes, depending on the trains' load factor and travel duration, but do not provide a full distribution of crowding costs.

Using information from a limited survey of line 1 during morning peaks, Haywood and Koning (2012) compare peak and off-peak travel preferences in Paris. They find WTTL estimates in the range of 5.7-8.1 minutes, implying crowding costs of $€ 1.01-1.46 /$ trip, i.e. around twice the average fare currently paid by the Parisian PT network's users, or an average Tm ranging from 1.3-1.4. However, the survey design suffered major weaknesses, especially with respect to the hypothetical changes proposed to PT users. It only considered the difference between peak and off-peak periods. Peak period density data were only available for the stations where individuals were interviewed, i.e. at the beginning of their trips. The hypothetical comfort

\footnotetext{
${ }^{8}$ The load factor is defined as the ratio of transport users over seating in public transport. As in-vehicle transport design varies considerably, we prefer to focus on user density by space (not seats).

${ }^{9}$ Based on a revealed preference study of route choices, Japanese Tm of 1.11-1.62 for load factors comprised between $110 \%$ and $260 \%$ are reported by ITF-OECD (2014) and Kato (2014).
} 
level (off-peak density) did not specify a particular level of density and was thus subjective. This only allowed an estimation of average crowding costs between peak and non-peak travel ${ }^{10}$.

Based mainly on stated preferences, Kroes et al. (2013) value crowding costs in various PT modes (subways, trains, buses, streetcars) of the Paris region. They interviewed around 3,000 PT users for time-comfort trade-offs and find $T m$ for subways ranging from 1 to 1.36 for seated trips and from 1.27 to 1.55 for standing trips, results below the British and Australian valuations but in line with those of Haywood and Koning (2012). The standing Tm found for subways and regional trains are similar (lower than for buses and streetcars). Interestingly, they find some statistical supports for a fixed (additive) penalty due to in-vehicle crowding, as opposed to the multiplicative specification largely put forward in the literature and presented above. In order to use the crowding values for policy analyzes, Kroes et al. (2013) however revert to the multiplicative form implied by $T m$ figures ${ }^{11}$.

Whereas these studies propose a variety of crowding valuations, they do not use the results to calibrate a function endogenizing the generalized cost of PT to the level of usage, as typically done for road congestion where the traffic determines the time costs through the so-called "speed-flow-density" relationship (Small and Verhoef (2007)).

Several theoretical specifications of PT usage costs with respect to the

\footnotetext{
${ }^{10}$ Furthermore, the previous survey used a non-random bidding process, which always started with a 5 minutes offer whilst adding a follow-up question only for individuals who accepted the initial trade-off. Finally, data on the in-vehicle travel duration relied only on self-reported trip duration.

${ }^{11}$ Kroes et al. (2013) also observe the number of individuals that let a train pass as a function of the level of crowding in trains arriving at stations. This revealed preferences approach confirms that the more crowded the trains, the more likely the people stay on platforms. The Tm found with this method are lower than those found with their contingent scenarios. Given the high uncertainty faced by travellers waiting on platforms about the crowding in the trains that will arrive, Kroes et al. (2013) use the Tm derived via stated preferences for policy analyses.
} 
level of patronage have been proposed in the literature. Thus Kraus (1991) differentiates the time value, depending on whether users can be seated in vehicles or if they have to stand. Jara-Diaz and Gschwender (2003) use a linear specification. The most recent contributions suggest using stepwise functions (de Palma et al. (2013), Feifei and Haicheng (2011)): First, the time value faces a discrete jump once the seating capacity is exhausted, then it remains constant and, finally, it increases exponentially for high levels of crowding. Although they allow accurate analyzes of PT crowding, these articles do not estimate their models using individual-level data.

Very few studies estimate a crowding cost function ${ }^{12}$. First, Hensher et al. (2011) estimate linear, quadratic and logarithmic relationships of WTP measures in the Sydney PT with respect to the number of people standing in vehicles and/or the probability of having a seat. Tirachini et al. (2013) and Tirachini et al. (2014) use the same Australian data set and similar crowding cost specifications. Their estimates are used to analyze the demand for PT from a modal choice perspective and the effects of in-vehicle crowding on the design and pricing of buses. Second, Whelan and Crockett (2009) use British stated preferences to estimate linear, exponential, power and Gompertz Tm-load factor functions. They find no empirical support for complex specifications, but do not illustrate the relevance of their relationship with concrete examples ${ }^{13}$.

The Tm found by Kroes et al. (2013) have recently been used by French authorities to propose a relationship between crowding costs and passenger density that should be used for official socioeconomic assessments of transport projects (Commissariat Général à la Stratégie et à la Prospective

\footnotetext{
${ }^{12}$ Apart from the articles cited here, Japanese official guidelines for socioeconomic assessment of transport projects use such relationships, differentiated for several levels of PT crowding (ITF-OECD (2014), Kato (2014)).

${ }^{13}$ Tirachini et al. (2010) use the time multipliers estimated by Whelan and Crockett (2009) to minimize costs of different types of PT for both users and operators. However, they calibrate a quadratic function in order to reach a numerical solution when solving their algorithm.
} 
(2013)). This relationship is shown to be linear for both seated and standing passengers. Finally, Prud'homme et al. (2012) also find support for a linear relationship between $W T P$ and passenger density in the Paris metro. They use the estimated relationship to assess investments projects and the optimal car-subway mix in the central city. However, Prud'homme et al. (2012) rely on the same survey data as Haywood and Koning (2012), which suffers from numerous shortcomings in the survey design discussed previously, notably the subjectivity and lack of variation of comfort conditions in the hypothetical scenarios.

The new survey allows us to focus better on the whole distribution of crowding costs which we then synthesize in a simple function. This function can be compared with the official values proposed by Commissariat Général à la Stratégie et à la Prospective (2013).

\section{Survey Design and Data}

Data were collected between November 2010 and January 2011 on lines 1 and 4 of the Paris subway. Interviews were carried out during extended morning and evening rush hours (between 7.30-10am and between 5-7.30pm), directly on the platforms of 11 representative stations ${ }^{14}$.

Crossing Paris East-West, line 1 is the busiest service of the Paris network (with 750,000 users per day). It connects the PT users to most of the strategic centers (economic, tourism) of Paris. Crossing Paris North-South, line 4 faces a smaller patronage than line 1 (670,000 users per day), but is the second busiest line of the network. Taken jointly, the two lines give access to the most important residential, touristic and business amenities of Paris, but also include some of the poorest neighbourhoods of the city. We interviewed

\footnotetext{
${ }^{14}$ Line 1, morning peak: Gare de Lyon, Hôtel de Ville and Champs-Elysées; Line 4, morning peak: Denfert-Rochereau, Montparnasse and Odéon; Line 1, evening peak: Esplanade de la Défense, Argentine, Georges $V$; Line 4, evening peak: Les Halles, Odéon and Saint-Sulpice.
} 
Le confort dans le métro parisien

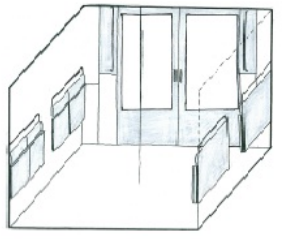

Carte 1

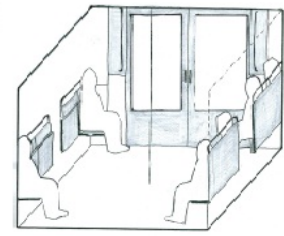

Carte 2

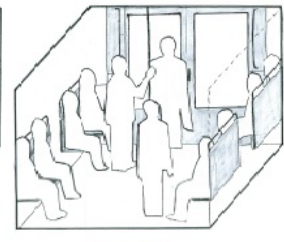

Carte 3
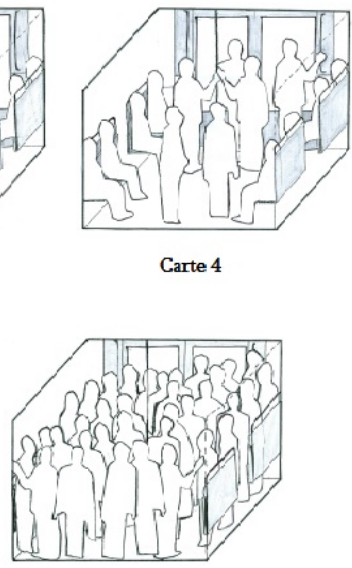

Carte 7

Figure 1: Showcard used during the field survey

respondents whilst they were waiting for their train in order to minimize bias stemming from selective non-response. The design of the questionnaire was specifically tailored to allow interviewers to complete the questionnaire in the 1-2 minutes between the passage of two trains. We believe that such a procedure (face-to-face survey completed in a limited time span) is more likely to provide representative answers compared to online or mail surveys where interviewees are not placed in "real world" conditions (Szolnoki and Hoffman (2013)).

\subsection{Temporal congestion reduction scenarios}

To describe the level of passenger density in PT, we use showcards (also implemented by Douglas and Karpouzis (2006), Whelan and Crockett (2009), Hensher et al. (2011), Basu and Hunt (2012) and Kroes et al. (2013)). First, users were asked to determine their expectation of passenger density during peaks (corresponding to $0,1,2,2.5,3,4$ or 6 passengers per square metre, 
see figure (1)) - this is the density that users expect to face in the train they are about to take. A hypothetical density reduction from this reference point was proposed (the density reduction was drawn from a uniform distribution). We then randomly proposed a first temporal bid $(3,6,9,12,15,18$ minutes, see appendix (7.2)): "In order to travel with this hypothetical level of comfort, instead of your current one, would you agree to use a subway which takes $X$ additional minutes to reach your destination?"

Whilst open questions or payment cards could provide more precise values, the binary format with discrete choices is said to better mimic individuals' everyday decisions (Haab and McConnel (2003)). Moreover, the second bid was increased (decreased) by $25 \%$ for individuals who accepted (refused) the first bid, in line with the "double-bounded" model largely used in environmental economics (see Hanemann et al. (1991) or Haab and McConnel (2003)). Note that the additional time proposed to users only concerns the in-vehicle travel duration, not the waiting time on platforms (which may be valued differently, see ITF-OECD (2014) or Douglas and Karpouzis (2006)). Also, our showcard does not allow us to differentiate whether individuals are standing or seated within carriages (for this, see Kroes et al. (2013), Whelan and Crockett (2009) or Hensher et al. (2011)).

In the context of PT comfort valuation, there are at least two advantages of not proposing monetary bids but rather phrasing bids in temporal terms: First, it reduces the risk that individuals freeride on others' contributions by under- or over-reporting (strategic bias, see Lu et al. (2008)) ${ }^{15}$. In our case this is particularly relevant as monetary costs are highly subsidised both publicly and by employers. Second, it makes it easier for individuals to envisage the proposed scenario (reducing the so-called hypothetical bias, see Hensher (2010)): travellers confronted with overcrowded vehicles sometimes let a train pass before taking a space on the next one (Kroes et al.

\footnotetext{
${ }^{15}$ "It is in the selfish interest of each person to give false signals, to pretend to have less interest in a given collective consumption activity than he really has." (Samuelson (1954))
} 
(2013)). Commuters may equally adjust their departure/arrival times in order to avoid congested trains (de Palma et al. (2013)), or adjust their routes accordingly (Leurent and Liu (2009), Raveau et al. (2011)).

Finally, we have independent information on trip conditions. The PT operator only provided us with limited information on average density for selected sections of lines 1 and 4 for 2008. Therefore we manually counted passenger density (for the section of carriages described by figure (1)) in January and February 2011 in over 80 trains. We also measured travel times necessary to connect different stations on lines 1 and 4 . These statistics allow us to reconstruct individuals' objective trip characteristics.

\subsection{Sample and Selection}

From an initial sample of 800 PT regular users $^{16}$ we have complete data for 668 individuals. Equal numbers of women and men were interviewed, with an average age of 35 years. $57 \%$ of respondents live in the centre of Paris $(62 \%$ of line 4 users and $53 \%$ in line 1), $94 \%$ in the greater Paris area. Only $38 \%$ of our sample owns a car. Average monthly income is $€ 2,440$ (higher in line 1 at $€ 2,798)$. Using this information, it is possible to calculate an individualised opportunity cost of time $w_{i}$ with a mean value of $€ 0.20$ per minute in $2010(€ 12 / \mathrm{h}$ ), close to the value implied by the official French guidelines (€10.70/h in 2010, see Commissariat Général à la Stratégie et à la Prospective (2013)). However, this value is found to vary considerably across lines and the time of day individuals travel - with important implications for the estimated congestion costs. Most trips concern commuting to and from the workplace (70\% overall, higher in line 1 and in the morning) and were taken daily (64\%) which should help individuals evaluate scenarios of reduced con-

\footnotetext{
${ }^{16}$ Interviewers asked PT users if they had already taken line 1 or 4 during rush hour at least once in the past. In order for the hypothetical scenarios to be realistic, we wanted to survey only individuals with prior experience of crowding in Paris subways, thus avoiding tourists.
} 
gestion. Mean reported door-to-door travel time was 46 minutes, in-vehicle trip duration $t_{i} 9.6$ minutes (11.5/7.9 in lines $\left.1 / 4\right)$ representing only $21 \%$ of total travel duration. The in-vehicle time budget corresponds to $€ 1.90 /$ trip and amounts to over three times the single fare paid by Parisian PT users. Because of higher opportunity cost and longer travel times, costs measured in terms of time are larger for line 1 (€2.65/trip versus $€ 1.34 /$ trip on line 4$)$.

Table 2: Respondents and trip characteristics

\begin{tabular}{|l|c|c|c|c|c|}
\hline & Total & Line 1 & Line 4 & Morning & Evening \\
\hline Age (years) & & & & & \\
Male (\%) & 55 & 36 & 34 & 35 & 35 \\
Parisian (\%) & 57 & 53 & 62 & 50 & 50 \\
Paris region (\%) & 94 & 94 & 95 & 56 & 59 \\
Car ownership (\%) & 38 & 43 & 33 & 39 & 96 \\
Income (€/month) & 2,440 & 2,798 & 2,097 & 2,589 & 37 \\
Time opportunity cost (€/min) & 0.20 & 0.23 & 0.17 & 0.21 & 0.19 \\
Home-to-Work (\%) & 70 & 78 & 62 & 76 & 64 \\
Daily use of line (\%) & 64 & 66 & 62 & 63 & 65 \\
Door-to-door travel time (min) & 46 & 47 & 44 & 51 & 41 \\
No. of stations travelled & 6.8 & 7.2 & 6.4 & 6.8 & 6.8 \\
In-vehicle travel time (min) & 9.6 & 11.5 & 7.9 & 9.4 & 9.9 \\
Distance travelled (km) & 3.8 & 5.1 & 2.6 & 3.7 & 3.9 \\
\hline
\end{tabular}

Sources: Field survey on platforms and RATP, i.e. the PT operator, website for distances' figures.

Notes: The average distance between stations strongly differs between lines 1 and $4(0.7 \mathrm{~km} /$ station and $0.4 \mathrm{~km} / \mathrm{station})$.

In order to entice individuals to truthfully reveal their income in a public space, we used a card representing 8 income categories, each with a different colour.

Following D4E (2005), we calculate the time opportunity cost $\left(w_{i}\right)$ from individual incomes $\left(y_{i}\right)$ by considering 135 worked hours per month: $w_{i}=(2 / 3) * y_{i} / 135$.

The response rate of PT users was around 60 percent. Interviewers were instructed to report estimated values for age and gender of individuals refusing to take part in the survey. Older individuals tend to participate less often, with no obvious gender differentials. We believe the sample to be representative of rush-hour passengers using the Parisian metro system, in- 
cluding individuals not residing in Central Paris ${ }^{17}$. To what extent can the estimated crowding costs be generalized to the whole population?

First, we focus on rush-hour traffic. Nearly $35 \%$ of traffic occurs during rush-hours, so results for rush-hour traffic cover a large fraction of all current metro users. Of course, it may be the case that individuals who are particularly sensitive to crowding may shift their journey out of the rush hour. However, we believe that many individuals face high scheduling costs (in form of constraints to arrive at a specific time at work, in particular) that reduce the impact of such strategies on selectivity of the sample. Furthermore, our sample covers the time period from 7.30am to 10am and from $5 \mathrm{pm}$ to $7.30 \mathrm{pm}$, with varying levels of crowding within this period. Most commuters will choose times of less crowding within this period, further reducing the effect of selection.

Second, we focus on current metro users. Results are not representative of the population at large - estimating taste for crowding parameters including automobile users, cyclists, and taking into account residency choices requires a full equilibrium model and is beyond the scope of this article. We believe that transport operators, policy-makers and transport researchers can nonetheless learn lessons from the costs on current PT users.

\subsection{Expected in-vehicle density}

Table (3) presents the distribution of the expected density in trains. Note that this information corresponds to the reference point for later scenarios of reduced congestion. Only $2 \%$ think they will find an empty seat (the threshold being 1 pass $/ \mathrm{m}^{2}$ on the showcard), with no single person expecting an empty train. At the other extreme, less than $10 \%$ of the sample expect to

\footnotetext{
${ }^{17}$ Appendix (7.1) contrasts our field survey data with a larger sample of Paris subway users during peaks, with similar values for observable characteristics. Szolnoki and Hoffman (2013) report several studies concluding that face-to-face surveys lead to more representative samples than phone or online surveys.
} 
face the worst travel conditions $\left(6 \mathrm{pass} / \mathrm{m}^{2}\right)$. This proportion is five times higher for line 1 (15\%) than for line 4 (3\%). As illustrated in table (4), average expected density is $3.1 \mathrm{pass} / \mathrm{m}^{2}$, with important variations between lines 1 and 4 (3.5 pass $/ \mathrm{m}^{2}$ versus 2.7 pass $\left./ \mathrm{m}^{2}\right)$ and between mornings and evenings $\left(2.9\right.$ pass $/ \mathrm{m}^{2}$ versus $\left.3.3 \mathrm{pass} / \mathrm{m}^{2}\right)$. These figures are highly correlated with the objective passenger density faced, on average, by users during their trips: 2.3 pass $/ \mathrm{m}^{2}$ considering the surveyed data; 1.7 pass $/ \mathrm{m}^{2}$ with the aggregated data from the PT operator for $2008^{18}$.

Table 3: Expected density

\begin{tabular}{|l|c|c|c|c|c|c|c|}
\hline Expected density (pass $/ \mathbf{m}^{2}$ ) & $\mathbf{0}$ & $\mathbf{1}$ & $\mathbf{2}$ & $\mathbf{2 . 5}$ & $\mathbf{3}$ & $\mathbf{4}$ & $\mathbf{6}$ \\
\hline Total (\%) & & & & & & & \\
\hline Line 1 (\%) & 0.0 & 2.3 & 16.6 & 27.8 & 23.9 & 20.5 & 8.8 \\
Line 4 (\%) & 0.0 & 1.2 & 8.5 & 20.4 & 25.8 & 28.9 & 15.2 \\
\hline Morning (\%) & 0.0 & 3.4 & 24.4 & 35.0 & 22.0 & 12.4 & 2.7 \\
Evening (\%) & 0.0 & 3.2 & 21.6 & 29.3 & 21.6 & 17.8 & 6.5 \\
\hline
\end{tabular}

Source: Field survey on platforms.

Table 4: Density indicators

\begin{tabular}{|l|c|c|c|c|c|}
\hline & Total & Line 1 & Line 4 & Morning & Evening \\
\hline Expected density (pass $/ \mathbf{m}^{2}$ ) & 3.1 & 3.5 & 2.7 & 2.9 & 3.3 \\
\hline Surveyed density (pass $/ \mathbf{m}^{2}$ ) & 2.3 & 2.9 & 1.5 & 2.4 & 2.3 \\
Reported density (pass $/ \mathbf{m}^{2}$ ) & 1.7 & 2.2 & 1.3 & 1.6 & 1.9 \\
\hline
\end{tabular}

Sources: Survey data (over 80 trains departures) and data provided by the operator RATP (2008).

\footnotetext{
${ }^{18}$ Exploratory estimates conducted by Haywood and Koning (2013) with an ordered logit confirm that reference points are significantly influenced by objective levels of density (surveyed data and reported data). In line with this information, the expected density appears to be higher for line 1 users and for individuals interviewed during evening peaks. The only individual characteristics affecting perception of density are monthly income and door-to-door travel time. Importantly, the in-vehicle travel time does not present any significant effect on the expected density.
} 


\subsection{Hypothetical scenarios}

We propose random (time) bids and random reductions in passenger density (appendix (7.2) shows the distributions). Table (5) shows that on average, passengers are offered a reduction in density of 1.8 pass $/ \mathrm{m}^{2}$, corresponding to $60 \%$ of baseline density. The average value of the first bid proposed to interviewees amounts to a lengthening of their trip by 8.7 minutes. Using the time opportunity cost, the temporal bid is equivalent to $€ 1.80$ per trip, close to the valuation of current in-vehicle travel time. The acceptance rate for the first bid is $42 \%$ (49\% in line 1 and $34 \%$ in line $4 ; 45 \%$ in the evening and $38 \%$ in the morning rush hour). These results are consistent with the data on objective congestion, but also with the idea that scheduling costs may be higher in the morning, reducing the ability of workers to increase their trip duration at this margin. Because less than $50 \%$ of the sample accepted the first hypothetical scenario, the second bid is slightly lower than the first ( 8 minutes). However, the rate of positive answers is stable accross rounds (42\%). Appendix (7.3) considers an alternative decomposition of descriptive statistics by sequences of responses to bids.

Table 5: Descriptive statistics on hypothetical scenarios

\begin{tabular}{|l|c|c|c|c|c|}
\hline & Total & Line 1 & Line 4 & Morning & Evening \\
\hline Expected density (pass $/ \mathbf{m}^{2}$ ) & 3.1 & 3.5 & 2.7 & 2.9 & 3.3 \\
Hypothetical density (pass $/ \mathbf{m}^{2}$ ) & 1.3 & 1.5 & 1.1 & 1.1 & 1.4 \\
\hline Bid 1 (minutes) & 8.7 & 8.5 & 8.9 & 8.8 & 8.6 \\
Answer 1 positive (\%) & 42 & 49 & 34 & 38 & 45 \\
\hline Bid 2 (minutes) & 8.0 & 8.1 & 7.9 & 7.9 & 8.2 \\
Answer 2 positive (\%) & 42 & 43 & 40 & 40 & 43 \\
\hline
\end{tabular}

Source: Field survey on platforms. 


\section{Empirical Study of the Stated Preferences}

Our econometric strategy to compute the $T m$ focuses on the parameters of the utility function ${ }^{19}$. Following the specification proposed in section (2), individuals faced with travel time $t_{i}$ and current level of comfort $j$ are now given the opportunity of improving their level of comfort in an hypothetical scenario $k=P$ at the cost of accepting longer travel time. The extra travel time is denoted by $b_{i}>0$ where $k \in(A, P)$ designates the actual and proposed states. Note that in the actual state $(k=A), b_{i}^{A}=0$ with utility given by

$$
U_{i, j}^{k}=\alpha^{k}+\theta p_{i}+\sum_{j=0}^{J} \beta_{j} c_{j}^{k}\left(t_{i}+b_{i}^{k}\right)+\delta X_{i}+\varepsilon_{i}^{k} .
$$

The utility cost of travel time depends only on density $j\left(\beta_{j}=\beta_{j}^{A}=\beta_{j}^{P}\right)$. By contrast, the constant $\alpha^{k}$ is allowed to differ across the actual and proposed states. This enables us to control for a potential tendency of individuals to prefer the hypothetical scenarios, conditional on any proposed improvements of travel conditions. Individuals acceptance of a bid $P$ is governed by

$$
\begin{aligned}
\operatorname{Prob}(\text { Accept }) & =\operatorname{Prob}\left(U_{i, j}^{P}>U_{i, j}^{A}\right) \\
& =\Phi_{\varepsilon}\left[\alpha^{*}+\sum_{j=0}^{J} \beta_{j}^{*}\left(c_{j}^{P} T_{i}^{P}-c_{j}^{A} T_{i}^{A}\right)\right]
\end{aligned}
$$

where $T_{i}^{k} \equiv\left(t_{i}+b_{i}^{k}\right), \sigma_{\varepsilon}^{2}$ the variance of the differenced error term $\varepsilon=\varepsilon_{i}^{P}-\varepsilon_{i}^{A}$ and $\Phi_{\varepsilon}$ the cumulative density function of $\varepsilon$. We normalize the differenced parameter $\alpha^{*}=\frac{\alpha^{P}-\alpha^{A}}{\sigma_{\varepsilon}^{2}}$ and the time marginal disutility $\beta_{j}^{*}=\frac{\beta_{j}}{\sigma_{\varepsilon}^{2}}$.

In this framework, the value of comfort in situation $j$ is described by the coefficient $\beta_{j}^{*}$. The marginal rate of substitution between travel at different

\footnotetext{
${ }^{19}$ An alternative would be to estimate the marginal willingness to pay for all pairs of reference and hypothetical densities on the basis of equation (2). However, sample sizes for the 21 pairs would be too small, see appendix (7.2).
} 
comfort levels (e.g. $j=0$ vs. $j=1$ ) is then given by the ratio of the two coefficients $\beta_{0}^{*}$ and $\beta_{1}^{*}$. This corresponds to the time multiplier.

We can test the restriction that congestion costs do not depend on individual characteristics $\left(\delta=\delta^{A}=\delta^{P}\right.$ in equation (4)). To do this, we include an interaction term of individual characteristics and travel time under different comfort conditions

$$
\delta X_{i}=\delta_{1} X_{i}+\sum_{j=0}^{J} c_{j}^{k} \delta_{2, j} X_{i}\left(t_{i}+b_{i}^{k}\right)
$$

The utility function used to evaluate the bid (4) is then given by

$$
U_{i, j}^{k}=\alpha^{k}+\theta p_{i}+\sum_{j=0}^{J} c_{j}^{k}\left(\beta_{j}+\delta_{2, j} X_{i}\right)\left(t_{i}+b_{i}^{k}\right)+\delta_{1} X_{i}+\varepsilon_{i}^{k},
$$

such that the probability of accepting a bid is

$$
\begin{aligned}
\operatorname{Prob}(\text { Accept }) & =\operatorname{Prob}\left(U_{i, j}^{P}>U_{i, j}^{A}\right) \\
& =\Phi_{\varepsilon}\left[\alpha^{*}+\sum_{j=0}^{J} \beta_{j}^{*}\left(c_{j}^{P} T_{i}^{P}-c_{j}^{A} T_{i}^{A}\right)+\delta_{1}^{*} X_{i}+\sum_{j=0}^{J} \delta_{2, j}^{*}\left(c_{j}^{P} T_{i}^{P}-c_{j}^{A} T_{i}^{A}\right) X_{i}\right],
\end{aligned}
$$

where $\delta_{z, j}^{*}=\frac{\delta_{z, j}^{P}-\delta_{z, j}^{A}}{\sigma_{\varepsilon}^{2}}$ for $z \in\{1,2\}$. The marginal disutility of travel duration at comfort level $j$ is now given by $\beta_{j}^{*}+\delta_{2, j}^{*} X_{i}$, thus varying with individuals' characteristics $X_{i}$. The parameter $\delta_{2, j}^{*}$ may be considered a sensitivity premium, in the sense that if certain individuals (with specific individual characteristics $X_{i}$ ) are more sensitive to comfort, this will show up in a significant value of $\delta_{2, j}^{*}$.

Lastly, we consider the effect of heterogeneity in marginal disutilities of 
travel time by differences in earnings. We value variations of travel times, for each level of crowding, at individuals' opportunity cost $w_{i}$ (determined by individuals' monthly net income, see notes in table (2)):

$$
\begin{aligned}
\operatorname{Prob}(\text { Accept }) & =\operatorname{Prob}\left(U_{i, j}^{P}>U_{i, j}^{A}\right) \\
& =\Phi_{\varepsilon}\left[\alpha^{*}+\sum_{j=0}^{J} \beta_{j}^{*} w_{i}\left(c_{j}^{P} T_{i}^{P}-c_{j}^{A} T_{i}^{A}\right)\right] .
\end{aligned}
$$

\subsection{Estimation methods}

By assessing which factors induce individuals to accept a given bid, we estimate the marginal disutility of travel time. The probabilistic choices of accepting the bids expressed by equations (5), (8) and (9) could be estimated with standard probit or logit models. However, every individual is confronted with two bids and we need to take into account the fact that the double-bounded model introduces interdependency between bidding rounds because the follow-up question is conditioned on individuals' answer to the first bid.

First, since the aim of the double-bounded model is to increase the precision of the estimates (Hanemann et al. (1991)) by increasing the bids for individuals willing to accept the first bid (increasing the likelihood of "YesNo" sequences of bid acceptance) or decrease the bid for individuals not willing to accept the first bid ("No-Yes" sequences), we may expect a negative correlation across bids as a result of the questioning technique. Second, individual time invariant heterogeneity in answering the two bids would lead to a positive correlation across questions - individuals with a high WTP for comfort (conditional on the other variables in the model) would be more likely to accept both the first and second bids. Third, CVM studies have found evidence of "starting point" biases (Haab and McConnel (2003)). In our double-bounded survey design we may in fact find "anchoring, shift and framing" biases (Flachaire and Hollard (2007)). 
Any of these effects would violate the assumption of independently and identically distributed answers, thus leading to biased estimates of $\beta_{j}^{*}$. Thus we focus on estimation methods that take into account the relationship between the two rounds. This interdependency of individuals' answers is rarely noted in PT crowding valuation studies (Li and Hensher (2011)). Hensher et al. (2011) and Tirachini et al. (2013) are notable exceptions.

Our first estimator is the bivariate probit model, initially implemented in evaluating non-market goods by Cameron and Quiggin (1994). This model estimates coefficients for both rounds of questions separately but assumes that the distribution of the error terms $\varepsilon$ across the two rounds is bivariate normal. No (further) restriction is posed on the covariance structure of the error terms and the degree of dependency is measured by the correlation coefficient between the error terms $(\rho)$.

Our second estimator focuses on the interdependence between the two bidding rounds induced by individual unobserved characteristics. We set up the data as a panel and we assume that individual time-invariant characteristics are not correlated with duration of the trips, that is, assume a random effects framework. This implies a restriction on the correlation of the error terms across rounds (necessarily positive). Since the two rounds of bidding are assumed to originate from the same vector of parameters, only one set of parameter estimates is generated by this estimator. The random effects estimators was first applied to the analysis of the double-bounded model by Alberini et al. (1997).

Both estimators provide us with measures of intra-class correlation, i.e. of the change in the propensity of the same individual to accept or reject a bid conditional on their answer to the first bid. The estimated parameter $(\rho)$ in the random effects model is the proportion of total variance accounted for by unobserved individual heterogeneity $\left(\rho \equiv \frac{\sigma_{u}^{2}}{\sigma_{\varepsilon}^{2}}\right)$. As noted, the bivariate 
probit estimates the correlation between the errors in the first and second round (assuming normality). If the error structure assumed by the random effects specification is correct, the interdependence across bidding rounds can be given by an additive separable component $u$ (such that $\varepsilon_{i, t}=\varepsilon_{i, t}^{*}+u_{i}$ ), and the two measures are equal since:

$$
\begin{aligned}
\rho_{\varepsilon_{1}, \varepsilon_{2}} & =\frac{\operatorname{cov}\left(\varepsilon_{1}, \varepsilon_{2}\right)}{\sigma_{\varepsilon_{1}} \sigma_{\varepsilon_{2}}} \\
& =\frac{\operatorname{cov}\left(\varepsilon_{1}^{*}+u, \varepsilon_{2}^{*}+u\right)}{\sigma_{\varepsilon_{1}^{*}+u} \sigma_{\varepsilon_{2}^{*}+u}} \\
& =\frac{\sigma_{u}^{2}}{\sigma_{\varepsilon^{*}}^{2}+\sigma_{u}^{2}} \\
& =\frac{\sigma_{u}^{2}}{\sigma_{\varepsilon}^{2}} \equiv \rho,
\end{aligned}
$$

where we assume equal variance of $\varepsilon_{1}^{*}$ and $\varepsilon_{2}^{*}$.

\subsection{Results}

Table (6) presents the effects of different levels of passenger density on the probability of accepting longer travel times for less crowded commuting conditions, i.e. on the disutility of trip duration. All levels of passenger density greater than 1 passenger per square meter significantly decrease individual utility (at the $1 \%$ level), whilst PT users prefer having some people around them rather than facing empty vehicles ${ }^{20}$.

The estimated value of $\rho$ is significantly positive both in the bivariate and the random effects estimations. This is consistent with the observed sequences of answers, with a higher proportion of users accepting or rejecting twice the contingent scenarios (see appendix (7.3)). A positive correlation of the error terms across answers is also prima facie evidence of individual

\footnotetext{
${ }^{20}$ We observe a flattening of decrease in marginal disutility for the worst travel conditions. This could be linked to measurement error in responses if certain respondents were not able to properly quantify the difference between highly congested situations 6 and 7 presented on the showcard (see figure (1)).
} 
Table 6: Discrete choices estimates

\begin{tabular}{|c|c|c|c|}
\hline & \multicolumn{2}{|c|}{ Bivariate Probit } & \multirow{2}{*}{$\begin{array}{c}\text { Random Effects } \\
\text { Both Bids }\end{array}$} \\
\hline & First Bid & Second Bid & \\
\hline $\begin{array}{l}\text { Marginal disutility of trip } \\
\text { duration by crowding: }\end{array}$ & & & \\
\hline 0 pass $/ \mathrm{m}^{2}$ & $\begin{array}{c}-0.124^{* * *} \\
(0.009)\end{array}$ & $\begin{array}{c}-0.148^{* * *} \\
(0.010)\end{array}$ & $\begin{array}{c}-0.200^{* * *} \\
(0.025)\end{array}$ \\
\hline 1 pass $/ \mathrm{m}^{2}$ & $\begin{array}{c}-0.116^{* * *} \\
(0.010)\end{array}$ & $\begin{array}{c}-0.155^{* * *} \\
(0.011)\end{array}$ & $\begin{array}{c}-0.200^{* * *} \\
(0.025)\end{array}$ \\
\hline $2 \mathrm{pass} / \mathrm{m}^{2}$ & $\begin{array}{c}-0.126^{* * *} \\
(0.010)\end{array}$ & $\begin{array}{c}-0.159^{* * *} \\
(0.011)\end{array}$ & $\begin{array}{c}-0.210^{* * *} \\
(0.026)\end{array}$ \\
\hline 2.5 pass $/ \mathrm{m}^{2}$ & $\begin{array}{c}-0.141^{* * *} \\
(0.010)\end{array}$ & $\begin{array}{c}-0.177^{* * *} \\
(0.011)\end{array}$ & $\begin{array}{c}-0.235^{* * *} \\
(0.028)\end{array}$ \\
\hline 3 pass $/ \mathrm{m}^{2}$ & $\begin{array}{c}-0.157^{* * *} \\
(0.012)\end{array}$ & $\begin{array}{c}-0.185^{* * *} \\
(0.012)\end{array}$ & $\begin{array}{c}-0.253^{* * *} \\
(0.031)\end{array}$ \\
\hline 4 pass $/ \mathrm{m}^{2}$ & $\begin{array}{c}-0.174^{* * *} \\
(0.012)\end{array}$ & $\begin{array}{c}-0.206^{* * *} \\
(0.014)\end{array}$ & $\begin{array}{c}-0.281^{* * *} \\
(0.034)\end{array}$ \\
\hline 6 pass $/ \mathrm{m}^{2}$ & $\begin{array}{c}-0.193^{* * *} \\
(0.015)\end{array}$ & $\begin{array}{c}-0.234^{* * *} \\
(0.016)\end{array}$ & $\begin{array}{c}-0.315^{* * *} \\
(0.039)\end{array}$ \\
\hline Constant & $\begin{array}{c}0.575^{* * *} \\
(0.083)\end{array}$ & $\begin{array}{c}0.763^{* * *} \\
(0.084)\end{array}$ & $\begin{array}{c}0.980^{* * *} \\
(0.176)\end{array}$ \\
\hline$\rho$ & $\begin{array}{l}0.601^{* *} \\
(0.045)\end{array}$ & & $\begin{array}{l}0.557^{*} \\
(0.065)\end{array}$ \\
\hline AIC & $3,065.6$ & & $1,543.8$ \\
\hline BIC & $3,153.9$ & & $1,590.5$ \\
\hline Observations & 668 & 668 & 668 \\
\hline
\end{tabular}

Note: Standard errors in parentheses ${ }^{*}: p<0.10 ;{ }^{* *}: p<0.05 ;{ }^{* * *}: p<0.01$. 


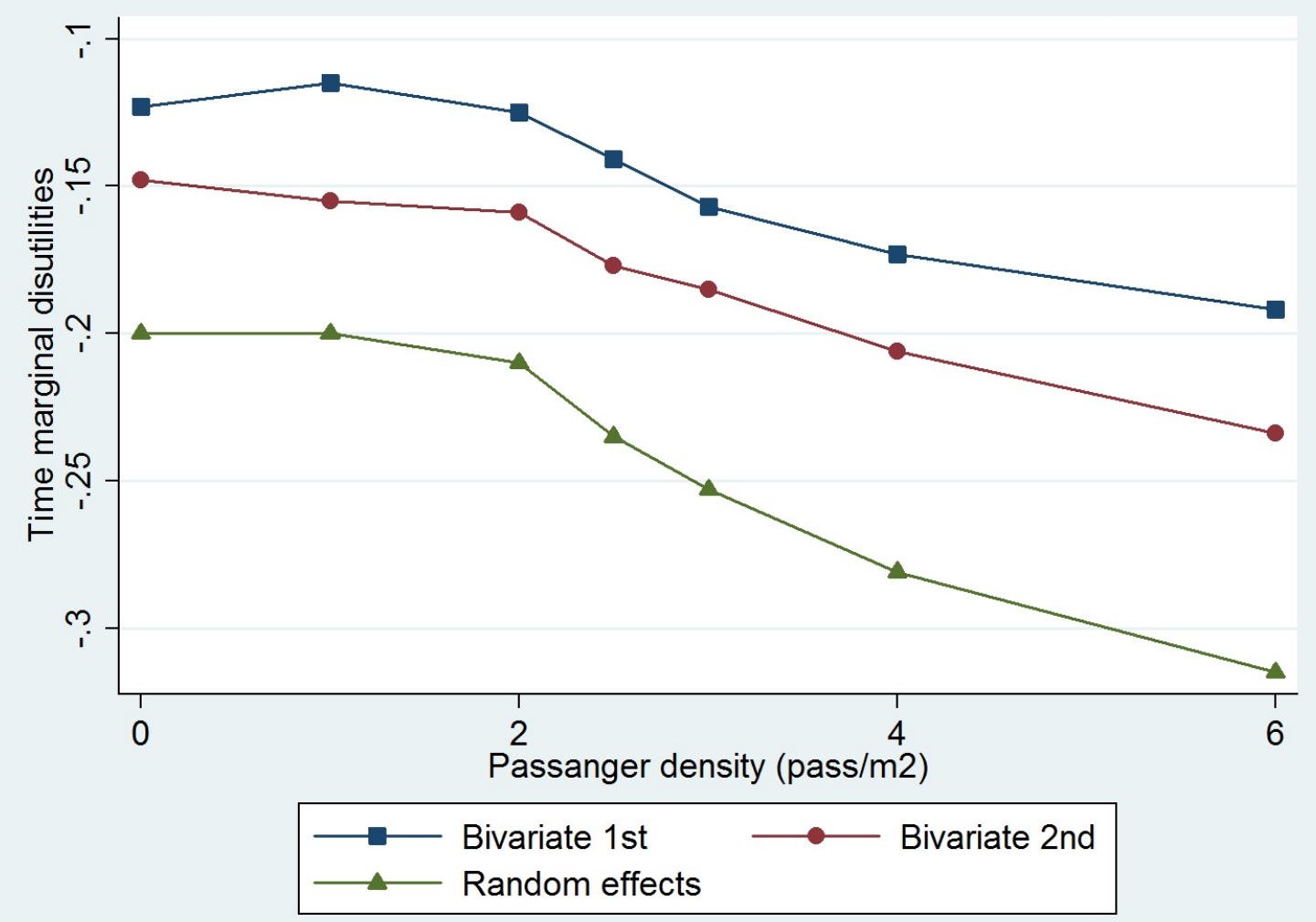

Figure 2: Travel time marginal disutilities

effects being more important than the effect of bid sequencing. Thus we believe the restriction of the random effects model and focus on the random effects results in what follows ${ }^{21}$. Figure (2) constrasts congestion cost estimates of the different estimators.

Focusing on the random effects results is only sensible if the estimates for the two rounds are not significantly influenced by starting point biases. In our bivariate probit results, the time disutilities estimated from the second bids lie within the confidence intervals of those obtained from the first round

\footnotetext{
${ }^{21}$ Both the Schwarz (BIC) and Aikaki (AIC) information criteria for model selection indicate that the random effects specification is preferred.
} 
bids (see figure (4) in appendix). This implies that whilst biases may exist ${ }^{22}$, they do not strongly influence estimated values of $\beta_{j}^{*}$. Compared to environmental studies that often find large differences in estimates across bidding rounds (see Haab and McConnel (2003), Flachaire and Hollard (2007)), these results suggest that the double bounded model may be particularly valuable for analyzing the qualitative attributes of PT. Furthermore, we believe that the realism of the hypothetical scenario plays in our favour here - how long to wait for a less congested train is easier to assess than the utility of not having an oil spill nearby.

We test the restriction that crowding costs are independent of observed individual characteristics (i.e. $\delta_{2, j}^{*}=0$ ). We thus estimate equation (8), introducing interactions of travel time with various individual characteristics (age, gender, reason for trip, place of residency, line, time of day, car ownership, line daily usage, door-to-door travel time). We find significant sensitivity premia $\left(\delta_{2, j}^{*}\right)$ only for the time of day dummy: for most levels of comfort, travel time appears to be more costly for morning commuters (see appendix (7.5)).

As a robustness test we have also used individualized time opportunity costs (based on earnings) to estimate $\beta_{j}^{*}$. Table (16) in appendix (7.6) shows that the marginal disutilities of travel times are clearly lower in that case. However, the shape of $\beta_{j}^{*}$ with respect to the level of passenger density is not affected.

Finally, a correlation between value of time and value of comfort may be possible on unobserved dimensions, so that people with short travel times value comfort less than those with long travel times. We have tested this in the following ways: First, the estimates were reproduced for individuals

\footnotetext{
${ }^{22}$ The constant specific term is highly significant, both in the bivariate and the random effects probit models. It is thus important to control for PT users' unexplained tendency to consent to proposed bids.
} 
with travel times below versus above the median in our sample (8.2 minutes). Differences in comfort valuations were not statistically significant across subsamples, whatever the level of comfort. Second, we consider a utility function where travel time and comfort interact in a quadratic way. Whereas the first order parameters remained stable (and consistent with those shown in table (6)), the second order terms were not statistically different from zero, except for the most congested situation (for which we have only relatively few observations, see table (3)). Both tests (available on request) suggest that the value of time and value of comfort are not strongly correlated.

\subsection{The time multipliers}

With these results, we can now calculate time multipliers $(T m)$ across different levels of comfort. In order to compute the $T m$, one first has to choose a reference level of congestion, i.e. a denominator. We could use the empty subway as benchmark (with 0 pass $/ \mathrm{m}^{2}$ ). However, calculating PT crowding costs with respect to empty subways appears inconsistent with the social utility of infrastructures ${ }^{23}$. Therefore we use the 1 pass $/ \mathrm{m}^{2}$ situation, with 2 seats (out of 8 ) still available ${ }^{24}$.

In table (7), we find that the value of $T m$ ranges from 1.05 (for crowding of 2 pass $\left./ \mathrm{m}^{2}\right)$ to $1.57\left(6 \mathrm{pass} / \mathrm{m}^{2}\right)$. This implies that travellers are indifferent between spending 1 minute in the worst travel conditions and being seated for 1.6 minutes. Figure (3) illustrates the increasing relationship between $T m$ and in-vehicle passenger density. Importantly, we cannot reject a linear relationship between $T m$ and in-vehicle density, as found by Whelan and Crockett (2009) or Commissariat Général à la Stratégie et à la Prospective (2013) and discussed below.

\footnotetext{
${ }^{23}$ The same is true for road congestion, where analyses sometimes calculate congestion costs with reference to an empty road (Small and Verhoef (2007)).

${ }^{24}$ Note also that the bivariate probit estimates from the first round suggest that PT users prefer this situation over the situation with no other passengers.
} 
Table 7: Random Effect estimates of the Time multipliers (standard errors)

\begin{tabular}{|c|c|c|c|c|c|}
\hline Density & $\mathbf{T m}$ & $\mathbf{T m}(\mathbf{m o r})$ & $\mathbf{T m}(\mathbf{e v e})$ & $\mathbf{T}(\mathbf{m} / \mathbf{e})$ & $\mathbf{T m}(\mathbf{e a r n i n g s})$ \\
& & & & & \\
\hline $0 \mathrm{pass} / \mathrm{m}^{2}$ & 1.00 & 1.02 & 0.93 & 1.68 & 1.04 \\
& $(0.91-1.08)$ & $(0.93-1.12)$ & $(0.78-1.08)$ & $(1.13-2.24)$ & $(0.91-1.17)$ \\
$1 \mathrm{pass} / \mathrm{m}^{2}$ & 1.00 & 1.00 & 1.00 & 1.53 & 1.00 \\
& & & & $(1.02-2.03)$ & \\
$2 \mathrm{pass} / \mathrm{m}^{2}$ & 1.05 & 1.06 & 1.06 & 1.52 & 1.13 \\
& $(0.97-1.13)$ & $(0.96-1.15)$ & $(0.91-1.21)$ & $(1.06-1.97)$ & $(1.01-1.25)$ \\
$2.5 \mathrm{pass} / \mathrm{m}^{2}$ & 1.18 & 1.19 & 1.18 & 1.54 & 1.36 \\
& $(1.07-1.28)$ & $(1.07-1.31)$ & $(0.99-1.36)$ & $(1.08-2.00)$ & $(1.20-1.52)$ \\
$3 \mathrm{pass} / \mathrm{m}^{2}$ & 1.26 & 1.24 & 1.29 & 1.47 & 1.50 \\
& $(1.13-1.39)$ & $(1.10-1.38)$ & $(1.05-1.53)$ & $(1.01-1.92)$ & $(1.30-1.70)$ \\
$4 \mathrm{pass} / \mathrm{m}^{2}$ & 1.40 & 1.52 & 1.31 & 1.78 & 1.57 \\
& $(1.25-1.56)$ & $(1.33-1.71)$ & $(1.06-1.56)$ & $(1.22-2.33)$ & $(1.36-1.78)$ \\
$6 \mathrm{pass} / \mathrm{m}^{2}$ & 1.57 & 1.46 & 1.67 & 1.34 & 1.83 \\
& $(1.35-1.80)$ & $(1.20-1.73)$ & $(1.27-2.06)$ & $(0.89-1.79)$ & $(1.56-2.09)$ \\
\hline
\end{tabular}

Source: Authors' calculations.

Notes: $T m($ mor $)$ refers to the time multiplier for the morning peak, Tm(eve) for the evening peak, $T(m / e)$ gives the relative disutility of travel time, i.e. the marginal rate of substitution of travel time between morning and evening peaks (at given levels of density) using random effects probit. Tm(earnings) refers to time multipliers using estimates based on individual's time opportunity costs. Confidence intervals (estimated with the delta method) are in brackets. 


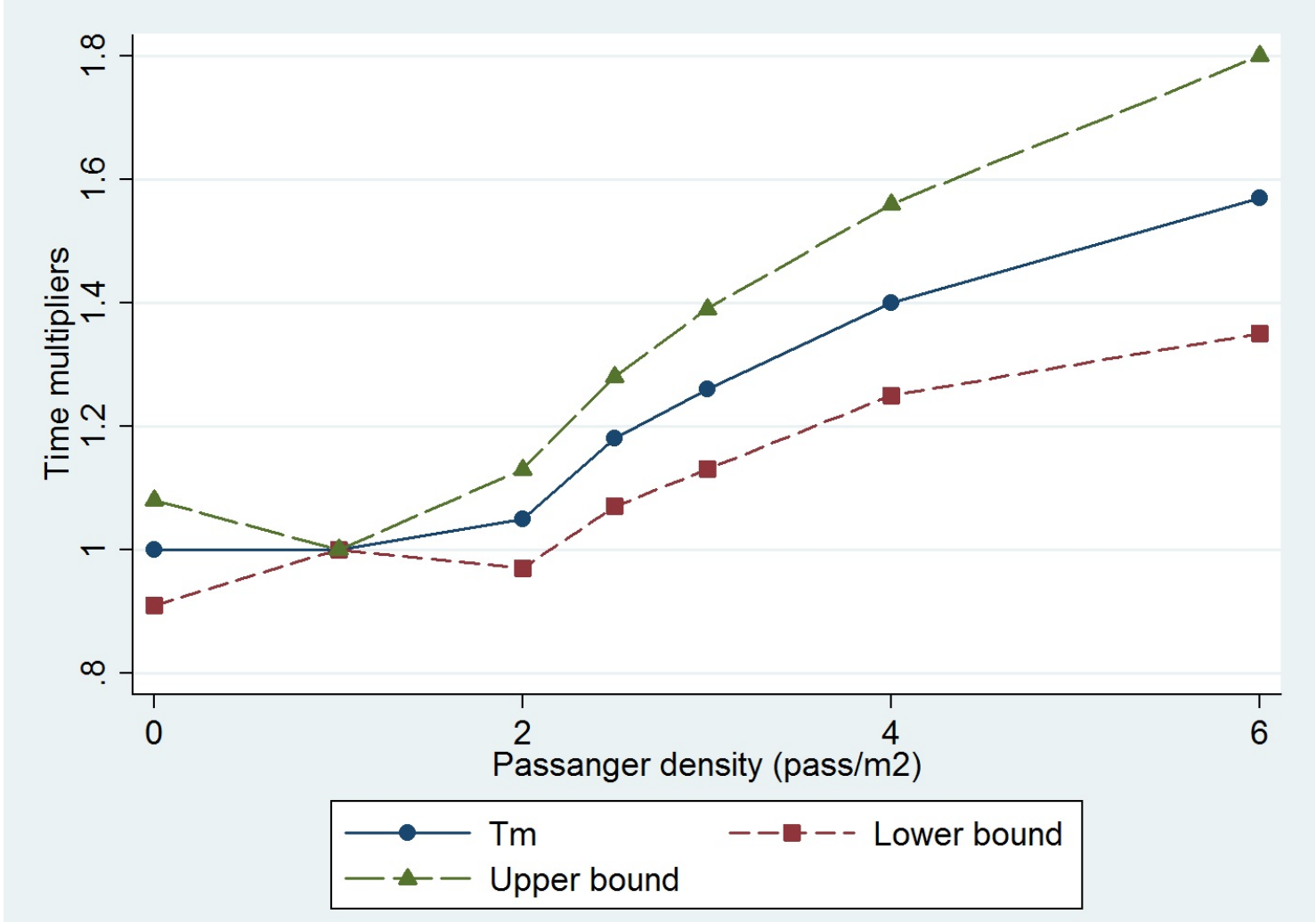

Figure 3: Time multipliers (in the benchmark case) and 95 percent confidence interval (estimated by the delta method) 
Comparing the value of $T m$ in the morning and evening peaks, we find a stronger relationship between density and congestion costs in the evening (the maximum $\operatorname{Tm}\left(\right.$ eve) is 1.67 at 6 pass $/ \mathrm{m}^{2}$ ). For the morning rush hour, the slope is less marked and the point estimate of Tm(mor) drops to 1.46 for the $6 \mathrm{pass} / \mathrm{m}^{2}$ situation, below the value associated with the $4 \mathrm{pass} / \mathrm{m}^{2}$ situation. We can use these estimates to compare the marginal disutility of travel time in the morning and evening peaks $(\mathrm{Tm}(\mathrm{m} / \mathrm{e}))$. Contrasting the two periods, the marginal rate of substitution between one minute during morning and evening peaks (for a given level of comfort) ranges from 1.34 to 1.78 . This implies that individuals are willing to trade one minute of morning commute with up to 1.78 minutes of commute in the evening, independent of the the level of crowding. This morning peak premium may be seen as a proxy for the higher scheduling costs in the morning linked to late arrivals at work and earlier departures from home (Arnott et al. (1990), de Palma et al. (2013)).

Finally, Tm based on individualised time costs (Tm(earnings)) are slightly higher than the values found in the benchmark case. Moreover, we find a fairly constant ratio using the common or individualized time multipliers: the latter are uniformly higher by around 10-20\%. We have no strong feelings about which measure should be used but focus on the benchmark (common) $T m^{25}$.

Reported crowding valuations appear to be consistent with the literature presented in section (2.2) - although values are somewhat lower than those of Wardman and Whelan (2011), Li and Hensher (2011) or Whelan and Crockett (2009), maybe because these authors mainly consider regional PT

\footnotetext{
${ }^{25}$ This has several reasons. First, we are taking a conservative approach to the estimation of comfort costs. Thus using the common measure reduces the monetary equivalent of time without affecting the relative profile of congestion costs. Second, the underlying rationale for using individual earnings as the opportunity cost of time appears particularly tenuous for our sample which includes a large proportion of salaried workers. Third, the common scheme is more in line with standard utilitarian measures giving every patron of the underground the same weight.
} 
networks rather than metropolitan ones. The distribution of Tm presented in table (7) is consistent with the values found by Kroes et al. (2013) using a different protocole. They find estimate time multipliers depending on crowding levels of $1.27,1.36,1.45,1.55$. As a consequence, these results stress that ignoring the discomfort effect may significantly alter the analyses of PT usage costs, as we now show.

\section{$5 \quad$ Policy Implications}

Our results point towards a linear relationship between crowding costs and density. Using the values from the random effects model (the first column in table (7)), we estimate a coefficient of 0.11 for the linearized relationship between the $T m$ and the level of density measured in pass $/ \mathrm{m}^{2}\left(d_{j}\right.$, such that $\left.c_{1}=1, \ldots, J \Rightarrow d=1,2, \ldots, J\right)$.

$$
\operatorname{Tm}\left(d_{j}\right)=d_{0}+0.11 d_{j}
$$

where $d_{0}=1$ is the normalized one-passenger-situation $\left(c_{j}=1\right.$ pass $/ \mathrm{m}^{2}$, $T m=1$, see figure (3)). The estimated relationship is similar to the official guideline presented by Commissariat Général à la Stratégie et à la Prospective (2013) who find a coefficient of 0.09 for standing trips based on estimates by Kroes et al. (2013).

\subsection{The Generalized Cost of Public Transport}

We use the time multiplier $\operatorname{Tm}\left(d_{j}\right)$ to add crowding costs to the generalized $\mathrm{PT}$ costs of money and in-vehicle travel time valued at the opportunity cost $w_{i}$.

$$
G C_{i}\left(d_{j}\right)=p_{i}+w_{i} t_{i} \operatorname{Tm}\left(d_{j}\right) .
$$

Table (8) gives estimated generalized costs using mean values for in-vehicle travel time, density and time opportunity cost, and assuming that $p_{i}=\mathrm{p}=0.50 €$ 
per $\operatorname{trip}^{26}$. We find that the generalized cost rises to $€ 3.07 /$ trip compared to $€ 2.42$ /trip when seating in trains is available. Neglecting PT crowding costs understates the welfare costs of rush-hour public transport by $27 \%$. Whilst the $G C\left(d_{j}\right)$ strongly differs between lines 1 and 4 (due to differences in trip durations and time opportunity cost), we do not observe any difference between morning and evening peaks (the higher opportunity cost in the morning counterbalancing the lower levels of density $)^{27}$. The average $T m$ ranges from 1.30 (line 4) to 1.39 (line 1), with a mean value of 1.34 . This corresponds to an increase in time value by $€ 0.07 / \mathrm{min}$, i.e. $€ 4.01 / \mathrm{h}$, based on time opportunity cost of $€ 12 / \mathrm{h}$. The average WTP is then $€ 0.66 /$ trip.

Table 8: Generalized costs, time multipliers and willingness to pay

\begin{tabular}{|l|c|c|c|c|c|}
\hline & Total & Line 1 & Line 4 & Morning & Evening \\
\hline GC(peaks) (€/pass) & 3.07 & 4.18 & 2.35 & 3.11 & 3.06 \\
GC(seat) (€/pass) & 2.42 & 3.15 & 1.84 & 2.47 & 2.38 \\
\hline Tm & 1.34 & 1.39 & 1.30 & 1.32 & 1.36 \\
WTTL (min/pass) & 3.3 & 4.5 & 2.4 & 3.0 & 3.6 \\
WTP (€/pass) & 0.66 & 1.04 & 0.41 & 0.63 & 0.68 \\
\hline
\end{tabular}

Source: Authors' calculations.

With these estimates we can calculate the welfare gains of reducing passenger density by $60 \%$ during peak periods. Applying the WTP of $€ 1.04$ /trip to the $35 \%$ of 750,000 daily rush-hour trips in line 1 , we find a potential welfare benefit of $€ 81.9 \mathrm{~m}$ on the basis of 300 commuting days per year. The same calculation for line 4 (670,000 users) gives a figure of $€ 28.8 \mathrm{~m}$. Assuming that our values for trip durations and estimated preferences are representative of the whole population of Paris PT users, we

\footnotetext{
${ }^{26}$ This corresponds to the average private cost of passengers net of public and employer subsidies.

${ }^{27}$ Estimates of the generalized costs are only little lower when using the objective density indicators (see table (4)): $G C($ peaks)=€2.91/trip with the count data and $G C($ peaks $)=€ 2.78 /$ trip with the data from the PT operator. Compared to the benchmark situation, this still implies a 15-20\% increase in the generalized cost of PT usage.
} 
can extend the analysis to the whole Paris subway network. With $517.7 \mathrm{~m}$ rush-hour trips in 2009 (Syndicat des Transports de la Région Ile-de-France (2009)) and an average WTP of $€ 0.66 /$ trip, we have potential benefits of $€ 341 \mathrm{~m}$.

Urban transport policies have understandably been attempting to increase the modal share of PT for environmental reasons and to enhance the attractiveness of city centres. The results here indicate that considerable welfare costs are imposed on existing users of PT without additional investment.

\subsection{The subway crowding externality}

Congestion is a non-market interaction that generates an external cost $\left(M C\left(d_{j}\right)\right)$ and calls for public interventions minimising the social cost of subway usage $\left(S C\left(d_{j}\right)\right)$. Following the Pigouvian framework that has been used to study road congestion (Small and Verhoef (2007)), we can write:

$$
S C\left(d_{j}\right)=G C\left(d_{j}\right)+M C\left(d_{j}\right)=G C\left(d_{j}\right)+\frac{\partial G C\left(d_{j}\right)}{\partial d_{j}} d_{j}
$$

Using our relationship between the time multiplier and passenger density, we distinguish the marginal cost of subway congestion from the generalized cost of PT usage. Table (9) shows that the average external cost per passenger in the Paris subway is $€ 0.63$. The social cost $\left(S C\left(d_{j}\right)\right)$ of PT usage reaches $€ 4.96$ per passenger for the most congested situation (for a $G C\left(d_{j}\right)$ of $€ 3.69)$. This compares to a benchmark $G C($.$) of € 2.42 /$ trip.

We can compare the valuation of the crowding externality to other nonmarket interactions linked to urban transportation (road congestion, accidents, noise, local pollutants, GHG). Table (10) shows that the marginal cost of subway congestion $(€ 0.17 / \mathrm{km})$ is $40 \%$ of the corresponding value for road congestion in Paris (€0.43/ km using Leurent et al. (2009) and our time value) - and exceeds estimates of the costs of environmental and phys- 
Table 9: Generalized, marginal and social costs of PT usage

\begin{tabular}{|c|c|c|c|c|}
\hline Density & $\begin{array}{c}\mathbf{G C}\left(d_{j}\right) \\
(€ / \text { pass })\end{array}$ & $\begin{array}{c}\mathbf{M C}\left(d_{j}\right) \\
(€ / \text { pass })\end{array}$ & $\begin{array}{c}\mathbf{S C}\left(d_{j}\right) \\
(€ / \text { pass })\end{array}$ & $\begin{array}{c}\mathbf{M C} / \mathbf{S C} \\
(\%)\end{array}$ \\
\hline 0 pass $/ \mathrm{m}^{2}$ & 2.42 & 0.00 & 2.42 & 0 \\
$1 \mathrm{pass} / \mathrm{m}^{2}$ & 2.42 & 0.00 & 2.42 & 0 \\
$2 \mathrm{pass} / \mathrm{m}^{2}$ & 2.84 & 0.42 & 3.26 & 13 \\
$2.5 \mathrm{pass} / \mathrm{m}^{2}$ & 2.95 & 0.53 & 3.48 & 15 \\
$3 \mathrm{pass} / \mathrm{m}^{2}$ & 3.05 & 0.63 & 3.68 & 17 \\
$4 \mathrm{pass} / \mathrm{m}^{2}$ & 3.26 & 0.84 & 4.10 & 20 \\
$6 \mathrm{pass} / \mathrm{m}^{2}$ & 3.69 & 1.27 & 4.96 & 26 \\
\hline
\end{tabular}

Source: Authors' calculations.

ical externalities due to dense automobile traffic $(€ 0.11 / \mathrm{km})^{28}$. This result is in line with those found by Tirachini et al. (2014) in Australian buses ${ }^{29}$. Above all, it highlights that PT crowding is a first-order urban externality that should clearly be considered by policy makers trying to reduce the use of cars in cities.

Table 10: Urban transport marginal costs

\begin{tabular}{|c|c|c|c|c|c|c|}
\hline & $\begin{array}{c}\text { Subway } \\
\text { congestion }\end{array}$ & $\begin{array}{c}\text { Road } \\
\text { congestion }\end{array}$ & $\begin{array}{c}\text { Cars } \\
\text { accidents }\end{array}$ & $\begin{array}{c}\text { Local } \\
\text { pollutants }\end{array}$ & $\begin{array}{c}\text { Cars } \\
\text { noise }\end{array}$ & $\begin{array}{c}\text { GHG } \\
\text { emissions }\end{array}$ \\
\hline$M C(€ / \mathbf{k m})$ & 0.17 & 0.43 & 0.07 & 0.02 & 0.01 & 0.01 \\
\hline
\end{tabular}

Sources: congestion.

\footnotetext{
${ }^{28}$ Since the values provided by the Handbook on estimation of external costs in the transport sector (Malibach et al. (2008)) are given in kilometric terms, we divide the marginal cost found previously for subways ( $€ 0.63 /$ pass at 3 pass $/ \mathrm{m}^{2}$ ) by the average distance of a trip performed in the Paris network (3.8 kilometres in our sample, see table (2)).

${ }^{29}$ Tirachini et al. (2014) estimate a crowding externality of 0.16-0.18 Australian dollars (AUD) for one kilometer travelled in buses. Using an exchange rate of $1 \mathrm{AUD}=0.7$ euro, this corresponds to $0.11-0.13$ euro $/ \mathrm{km}$.
} 
The estimated values of $M C\left(d_{j}\right)$ in table (9) could also be used as proxies for a policy of Pigouvian taxation aiming at internalizing the social cost of subway usage ${ }^{30}$. Whereas fares do not vary by time of day in Paris, they are increased by 30-70\% during rush hours in the London underground network.

\subsection{Line 1 automation}

We argue that taking into consideration the benefits of subway decongestion may significantly alter the Net Present Value $(N P V)$ and the Internal Rate of Return (IRR) of new transport projects (e.g. trams, bicycle or bus lanes), especially if they attract users from heavily congested subways. An example is the automation of line 1 . Since late 2012, line 1 runs without drivers, allowing more flexibility and greater reliability by finetuning the supply of line 1 to varying demand. We assess three effects of line 1 automation on the welfare of subway users:

First, during peaks, line 1 automation increases trains' frequency by $20 \%$, rising from 105 seconds between trains to 85 seconds (Régie Autonome des Transports Parisiens (2011)). Reduced waiting times generate an estimated gain of $€ 3 \mathrm{~m}$ for line 1 commuters $^{31}$.

Second, the average rush-hour speed of line 1 increased by 10\% (Régie Autonome des Transports Parisiens (2011)). Given an average trip duration of 11.5 minutes in rush hours (see table (2)), in-vehicle travel time drops to 10 minutes.

\footnotetext{
${ }^{30}$ It should be noted that our cost estimates are not equivalent to the optimal tax level, which would cover the - lower - level of crowding costs at the optimal level of PT usage.

${ }^{31}$ Assuming a uniform distribution of arrivals on platforms, mean waiting times will drop from 53 seconds to 43 seconds. The value of waiting time on platforms is multiplied by 1.5 vis-à-vis in-vehicle value (as recommended by Commissariat Général à la Stratégie et à la Prospective (2013)). 10 seconds waiting time * time opportunity cost in seconds $€ 0.23 / 60 * 262,500$ trips in peaks $* 300$ commuting days per year $* 1.5$ for platform waiting $=€ 3.0 \mathrm{~m}$.
} 
Third, assuming a constant peak demand for line 1, trains' higher frequency implies that the (reduced) in-vehicle time is consumed with more comfortable travel conditions. Thus, the average density $\left(3.5 \mathrm{pass} / \mathrm{m}^{2}\right.$, see table (2)) will decrease by $20 \%$, falling to $2.9 \mathrm{pass} / \mathrm{m}^{2}$.

Commuters' gains from faster trains and more comfort amount to $€ 49.6 \mathrm{~m}$ per year in generalized costs (a reduction of $€ 0.63$ per trip) ${ }^{32}$. For commuters, roughly $25 \%$ of the benefit accrue as a result of lower crowding costs - currently not taken into account in standard cost-benefit analysis.

Assuming gains for in-vehicle travel time are also extended to non-peak periods (with no reduction in crowding or waiting times in these periods), non-commuters gain a total of $€ 50.5 \mathrm{~m}^{33}$. Taken jointly, the annual benefits for line 1 users induced by automation reach $€ 103.1 \mathrm{~m}, 12 \%$ of which arise as a result of decreased peak crowding.

In order to calculate the $N P V$ of the investment, we consider the initial cost of $€ 629 \mathrm{~m}$. Given the social cost of raising public funds by taxation, French guidelines suggest augmenting public spendings by a factor of 1.25 (Commissariat Général à la Stratégie et à la Prospective (2013)). Following these rules, the $N P V$ of line 1 automation is $€ 554.9 \mathrm{~m}$ over a 20 years horizon applying a 4.5\% discount rate (Commissariat Général à la Stratégie et à la Prospective (2013)). This corresponds to the discounted value of the time resources saved by the project, net of the financial costs. The $I R R$ is $12 \%$, well above the $4.5 \%$ threshold considered as the minimal required level of profitability for transport projects in France. Line 1 automation seems to be a worthwhile project.

\footnotetext{
${ }^{32}$ Incorporating our time multiplier (equation (10)) in our formula for the generalized cost (equation (11)) we find generalized costs per passenger prior to automation of $G C_{0}=$ $0,5+11.5 * 0.23 *(1+0.11 * 3.5)=€ 4.16$. With automation we have $G C_{1}=0.5+10 *$ $0.23 *(1+0.11 * 2.9)=€ 3.53$, hence the gain of $€ 0.63$ per trip.

${ }^{33} 1.5$ minutes travel time at time opportunity cost $€ 0.23$ gained in 487,500 trips on 300 days.
} 
Although this cost-benefit analysis cannot take into account all impacts, we consider our assumptions to be fairly plausible, since other parameters were largely unchanged: The new carriages in line 1 offer approximately the same number of places as the old ones (720 places per train $)^{34}$. In addition, the PT operator promised unions that subway automation was not implemented in order to save labour costs. Finally, whilst we assume a constant demand in line 1 , faster and more comfortable travel conditions may actually attract users from other services ${ }^{35}$. This is irrelevant for our calculation however: given the linearity of the $T m$-passenger density relationship, benefits of lower density in other PT systems perfectly compensate reduced comfort gains in line 1.

\section{Conclusion}

Using new data from a survey of Paris subway users we describe the relationship between crowding in public transport and the utility cost of travel time. Using a contingent valuation methodology (CVM) we propose individuals' a trade-off between (increased) travel time and (decreased) passenger density in vehicles. Whereas the typical private monetary cost of a trip was $€ 0.50$, we found a monetized total trip cost of $€ 2.42$ for a seated passenger and around $€ 3.69$ under the most congested conditions. Our empirical results also allow us to approximate the marginal cost of subway crowding (€0.63/trip), a first-order urban externality, and to calculate the opportunity cost of transport time as a function of in-vehicle density (making the time multiplier a function of crowding). The value of travel time has to be

\footnotetext{
${ }^{34}$ Moreover, the old carriages of line 1 have been moved on line 4 whose former trains counted 700 places, i.e. a $3 \%$ increase in line 4 supply, keeping trains' frequency constant.

${ }^{35}$ A close substitute on part of the line 1 is the regional train service RER A. Transporting $1 \mathrm{~m}$ passengers per day, it serves 5 stations in common with line 1 in central Paris (Nation, Gare de Lyon, Chatelet, Charles de Gaulle, La Défense). RER A is around 15\% faster than line 1, but with a $30 \%$ higher passenger density.
} 
increased by $34 \%$ in order to account for crowding during peaks in Paris subways.

Individuals' stated preferences for less crowding appear robust and fairly consistent across bidding rounds (contrary to findings in environmental valuation research). A recent research paper commissioned by the Parisian PT regulator finds similar time multipliers to this article (Kroes et al. (2013)). This means that policy-makers can be confident about the crowding costs in Paris. However, it may not generalize to other cities, as the British experience suggests (Wardman and Whelan $(2011))^{36}$.

Whilst models used to evaluate transport policies recognise the existence of PT crowding, typically the calibrations do not give significant weight to this factor. First, the design of PT networks needs to focus not only on the duration of trips, but also on crowding. Second, policies aimed at incentivising modal shift should fully factor in the effect of increased PT usage on current users. This underlines the necessity of accompanying modal shift policies focusing on restrictions for road transport with increased investment in PT infrastructure. We provide evidence for the Parisian case. In an application to a recent infrastructure project we find additional gains resulting from lower crowding that are non-negligible compared to the benefits from faster services - but are largely ignored in economic apraisals. Inclusion of crowding costs in economic appraisals of transport projects is facilitated due to the near-linearity of the crowding cost function.

\footnotetext{
${ }^{36}$ The new official guideline for transport analysis (Commissariat Général à la Stratégie et à la Prospective (2013)) proposes crowding costs to be used in assessments of transport projects in France. The values included there are based on the Parisian case, which we doubt are relevant in small towns, although they may be correct for other large cities.
} 


\section{Acknowledgements}

This study was carried out without private or public funding. Survey design and data collection were made possible thanks to many volunteers. Among the main contributors we would like to thank Mélanie Babès for help with survey design and data collection, Cécile Peillon for help with the design of the showcard, Cindy Balmat and Jérémy Boccanfuso for help with data processing. M. Loknar from the subway operator RATP was also of assistance. Matthieu de Lapparent and Guillaume Hollard also provided us with useful comments. The usual disclaimer applies. 


\section{Appendix}

\subsection{Sample representativeness}

To test the representativeness of our sample for all rush-hour metro users in Paris, we compare our data with the best other dataset available, the "Enquête Globale Transport" (EGT), an extensive household survey conducted every 10 years in the Paris region. The last wave was collected in 2010 and interviewed around 18,000 households. We have extracted data for rushhour metro users (generating a sample of 2,414 individuals). Note that, as required, this represents rush-hour passengers using the whole subway network and not only lines 1 or 4 . Table (11) finds both populations to be rather similar. We highlight three differences:

First, whereas our sample has an equal share of men and women, the EGT reports only $45 \%$ men. This small gap may be related to line 1 serving La Défense (Paris Central Business District), where numerous executives work. At the national level, whereas $19 \%$ of men are executives, the figure is only $14 \%$ for women (Ministère des droits des femmes (2012)).

Second, the average age in our sample is 35 years - for this calculation we assume individuals' age is the median of the chosen category (assuming 15 and 70 years for the highest and lowest age categories respectively). The same calculation for EGT gives an average age of 39 years. Our sample is

younger because old people were less likely to take part in the survey (see section (3.2)). Also, line 4 serves several universities and high-schools.

Third, individuals in our sample are slightly more likely to own a car than in the EGT (38\% and $33 \%$ respectively). This small difference may be explained by the lower share of Paris inhabitants within our sample (57\% vs. $62 \%$ for EGT) given that the motorization rate of Paris inhabitants is lower than that of the suburbs. The reduced share of Parisians in our sample could also be explained by the fact that La Défense attracts people from the 
whole Paris region.

The stated average income levels are quite similar. However, it is not easy to compare these as the categories of net monthly income do not match. Following the same procedure as for age categories outlined above, we find an average of 2,440 euros/month in our sample and of 2,670 euros/month for EGT. This $9 \%$ difference can have two explanations. First, the EGT sample is $11 \%$ older than ours. Given the positive relationship between age and income, this may explain part of the difference. Second, individuals asked on subway platforms may be hesitant to publicly state their true earnings. Our strategy of using colour showcards may not have completely eliminated this issue.

Concerning the two last variables (trip purpose and total trip duration), the differences can be explained by line 1 too. La Défense concentrates many jobs and the surveyed people in our sample probably commute more than what is found with EGT ( $70 \%$ vs. 56\%). Lastly, many people working in la Défense do not live in central Paris (see above). As a consequence their total travel time is slightly higher (46 minutes vs. 42 minutes in EGT).

We conclude that our sample is fairly representative of the rush-hour Parisian subway users. Ideally, we would use detailed information on the true population of lines 1 and 4 users. We could then see whether the differences between our sample and the EGT are a result of sampling error or the result of the specificities of lines 1 and 4. Unfortunately this information is not available however.

\subsection{Description of contingent scenarios}

Table (12) gives the distribution of the hypothetical passenger density proposed to subway users as a function of PT users' current (expected) levels 
Table 11: Individual and journey characteristics for our sample and for EGT

\begin{tabular}{|c|c|c|c|c|}
\hline \multicolumn{2}{|l|}{ Variable } & \multirow{2}{*}{$\begin{array}{l}\text { Our } \\
\text { sample } \\
668\end{array}$} & \multicolumn{2}{|l|}{ EGT } \\
\hline Size of sample & & & 2,414 & \\
\hline \multirow[t]{2}{*}{ Gender } & Woman & $50.0 \%$ & $55.1 \%$ & \\
\hline & Man & $50 \%$ & $44.9 \%$ & \\
\hline \multirow[t]{7}{*}{ Age (Years) } & $<20$ & $7.0 \%$ & $2.8 \%$ & $(5-14)$ \\
\hline & $20-30$ & $35.3 \%$ & $17.1 \%$ & $(15-24)$ \\
\hline & $30-40$ & $26.0 \%$ & $21.6 \%$ & $(25-34)$ \\
\hline & $40-50$ & $18.5 \%$ & $38.7 \%$ & $(35-54)$ \\
\hline & $50-60$ & $10.2 \%$ & $11.5 \%$ & $(55-64)$ \\
\hline & $>60$ & $3.0 \%$ & $3.4 \%$ & $(64-74)$ \\
\hline & & & $2.9 \%$ & $(>74)$ \\
\hline \multirow[t]{2}{*}{ Car available } & Yes & $38.1 \%$ & $33 \%$ & \\
\hline & No & $61.9 \%$ & $66.5 \%$ & \\
\hline \multirow[t]{9}{*}{ Net income (euros/month) } & $<800$ & $16.0 \%$ & $4.4 \%$ & $(<800)$ \\
\hline & $800-1500$ & $12.3 \%$ & $6.1 \%$ & $(800-1200)$ \\
\hline & $1500-1800$ & $11.7 \%$ & $10.1 \%$ & $(1200-1600)$ \\
\hline & $1800-2100$ & $14.2 \%$ & $9.5 \%$ & $(2000-2400)$ \\
\hline & $2100-2500$ & $13.8 \%$ & $10.9 \%$ & $(2400-3000)$ \\
\hline & $2500-3000$ & $13.4 \%$ & $8.2 \%$ & $(3000-3500)$ \\
\hline & $3000-4000$ & $10.2 \%$ & $11.7 \%$ & $(3500-4500)$ \\
\hline & 4000-10000 & $6.4 \%$ & $7.6 \%$ & $(4500-5500)$ \\
\hline & $>10000$ & $2.1 \%$ & $15.7 \%$ & $(>5500)$ \\
\hline \multirow[t]{2}{*}{ Residence } & in Paris & $57.3 \%$ & $61.6 \%$ & \\
\hline & outside Paris & $42.7 \%$ & $38.4 \%$ & \\
\hline \multirow[t]{2}{*}{ Trip motive } & Work & $70.0 \%$ & $56 \%$ & \\
\hline & Other & $30.0 \%$ & $44 \%$ & \\
\hline Total travel time (minutes) & & 46.0 & 41.5 & \\
\hline
\end{tabular}


of density as indicated in the survey, i.e. the comfort reference point they expect to face in trains once the interview is finished.

Table 12: Hypothetical levels of comfort proposed to PT users

\begin{tabular}{|c|c|c|c|c|c|c|}
\hline Expected density $\left(\right.$ pass $/ \mathbf{m}^{2}$ ) & $\mathbf{1}$ & $\mathbf{2}$ & $\mathbf{2 . 5}$ & $\mathbf{3}$ & $\mathbf{4}$ & $\mathbf{6}$ \\
\hline Hypothetical density: & & & & & & \\
0 pass $/ \mathrm{m}^{2}$ (pct interviewees) & 100.0 & 51.3 & 30.0 & 26.4 & 19.4 & 16.7 \\
1 pass $/ \mathrm{m}^{2}$ & & 48.7 & 31.4 & 21.6 & 20.9 & 8.3 \\
2 pass $/ \mathrm{m}^{2}$ & & & 38.6 & 31.0 & 21.6 & 16.7 \\
$2.5 \mathrm{pass} / \mathrm{m}^{2}$ & & & & 21.0 & 20.1 & 18.3 \\
3 pass $/ \mathrm{m}^{2}$ & & & & & 18.0 & 13.3 \\
4 pass $/ \mathrm{m}^{2}$ & & & & & & 26.7 \\
\hline
\end{tabular}

Table (13) presents the distribution of the additional travel time that PT users must accept in order to enjoy more comfortable travel conditions. We targetted the distribution of answers found by Haywood and Koning (2012) during the first survey in line 1: only $5 \%$ of individuals accepted time bids above 15 minutes.

Table 13: Distribution of the first time bid proposed to PT users

\begin{tabular}{|l|c|c|c|c|c|c|}
\hline & 3 min. & 6 min. & 9 min. & 12 min. & 15 min. & 18 min. \\
\hline Pct of interviewees & 21.5 & 27.8 & 16.0 & 14.7 & 14.0 & 6.0 \\
\hline
\end{tabular}

Source: Field survey on platforms.

\subsection{Descriptive statistics by sequence of bidding answers}

Table (14) shows that $25 \%$ of subway users accepted both time bids ("YesYes"). This proportion is higher for line 1 users (59\% of the "Yes-Yes" 
respondents) and for evening trips (57\%). At the other extreme, we observe that $41 \%$ of the sample rejected twice the trade-off between travel time and comfort ("No-No"). This category is over-represented in line 4 (56\%) and during morning peaks (54\%). Whilst this information is consistent with the variations of current in-vehicle comfort across lines and periods, it may also be explained by the hypothetical extra travel time proposed to users: the first bid proposed to those who rejected the hypothetical scenario was twice the one faced by individuals accepting it (5.3 minutes and 10.9 minutes respectively).

Table 14: Descriptive statistics on hypothetical scenarios (2)

\begin{tabular}{|l|c|c|c|c|}
\hline & Yes-Yes & Yes-No & No-Yes & No-No \\
\hline Total (\%) & 25 & 17 & 17 & 41 \\
\hline Line 1 (\%) & 59 & 59 & 43 & 44 \\
Morning (\%) & 43 & 47 & 54 & 54 \\
\hline Expected density (pass $/ \mathbf{m}^{\mathbf{2}}$ ) & 3.3 & 3.3 & 3.0 & 3.0 \\
Hypothetical density (pass $/ \mathbf{m}^{2}$ ) & 1.2 & 1.3 & 1.1 & 1.3 \\
\hline Bid 1 (min) & 5.3 & 8.6 & 8.5 & 10.9 \\
Bid 2 (min) & 6.9 & 10.9 & 6.2 & 8.3 \\
\hline
\end{tabular}

Source: Field survey on platforms. 


\subsection{Bivariate probit estimates' confidence intervals}

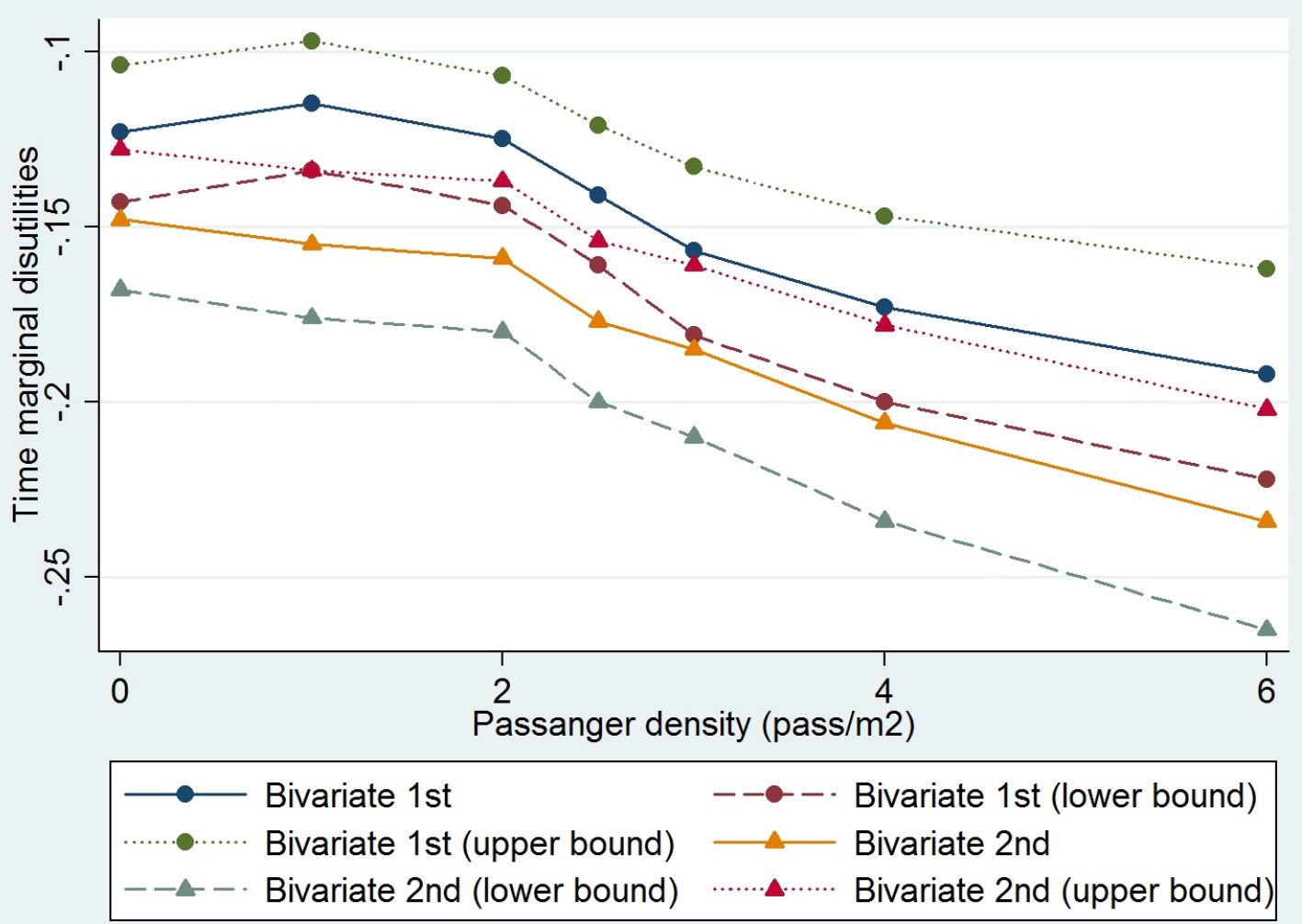

Figure 4: Confidence intervals (estimated bivariate probit) 
7.5 Time of day and marginal disutility of travel time

Table 15

\begin{tabular}{|l|cc|}
\hline $\begin{array}{l}\text { Marginal disutility } \\
\text { of travel time }\end{array}$ & $\begin{array}{c}\text { Random effects } \\
\text { probit }\end{array}$ & $($ s.e. $)$ \\
\hline 0 pass $/ \mathrm{m}^{2}$ & $-0.149^{* * *}$ & $(0.026)$ \\
$1 \mathrm{pass} / \mathrm{m}^{2}$ & $-0.160^{* * *}$ & $(0.028)$ \\
$2 \mathrm{pass} / \mathrm{m}^{2}$ & $-0.170^{* * *}$ & $(0.027)$ \\
$2.5 \mathrm{pass} / \mathrm{m}^{2}$ & $-0.189^{* * *}$ & $(0.030)$ \\
$3 \mathrm{pass} / \mathrm{m}^{2}$ & $-0.207^{* * *}$ & $(0.033)$ \\
$4 \mathrm{pass} / \mathrm{m}^{2}$ & $-0.210^{* * *}$ & $(0.034)$ \\
6 pass $/ \mathrm{m}^{2}$ & $-0.267^{* * *}$ & $(0.042)$ \\
& & \\
Morning commute $* 0$ pass $/ \mathrm{m}^{2}$ & $-0.102^{* * *}$ & $(0.032)$ \\
Morning commute $* 1$ pass $/ \mathrm{m}^{2}$ & $-0.085^{* * *}$ & $(0.033)$ \\
Morning commute $* 2$ pass $/ \mathrm{m}^{2}$ & $-0.088^{* * *}$ & $(0.032)$ \\
Morning commute $* 2.5 \mathrm{pass} / \mathrm{m}^{2}$ & $-0.102^{* * *}$ & $(0.036)$ \\
Morning commute $* 3$ pass $/ \mathrm{m}^{2}$ & $-0.097^{* *}$ & $(0.040)$ \\
Morning commute $* 4$ pass $/ \mathrm{m}^{2}$ & $-0.163^{* * *}$ & $(0.045)$ \\
Morning commute $* 6$ pass $/ \mathrm{m}^{2}$ & $-0.090^{*}$ & $(0.054)$ \\
& & \\
Morning commute & 0.374 & $(0.272)$ \\
& & \\
Constant & $0.802^{* * *}$ & $(0.216)$ \\
\hline$\rho$ & $0.535^{*}$ & $(0.068)$ \\
\hline Log pseudo & -752.2 & \\
Observations & 668 & \\
\hline
\end{tabular}

Note: ${ }^{*}: p<0.10 ;{ }^{* *}: p<0.05 ;{ }^{* *}: p<0.01$.

\subsection{Marginal disutility of travel time, valued at individuals' time opportunity cost}


Table 16: Discrete choices estimates (random effects probit), using common vs. individualized time opportunity cost

\begin{tabular}{|c|c|c|}
\hline & Common & Individualized \\
\hline $\begin{array}{c}\text { Marginal disutility of trip } \\
\text { duration by crowding: } \\
0 \text { pass } / \mathrm{m}^{2}\end{array}$ & $-0.200^{* * *}$ & $-0.509^{* * *}$ \\
& $(-0.249,-0.151)$ & $(-0.638,-0.379)$ \\
1 pass $/ \mathrm{m}^{2}$ & $-0.200^{* * *}$ & $-0.489^{* * *}$ \\
& $(-0.250,-0.150)$ & $(-0.614,-0.364)$ \\
2 pass $/ \mathrm{m}^{2}$ & $-0.210^{* * *}$ & $-0.554^{* * *}$ \\
& $(-0.260,-0.160)$ & $(-0.689,-0.418)$ \\
$2.5 \mathrm{pass} / \mathrm{m}^{2}$ & $-0.235^{* * *}$ & $-0.664^{* * *}$ \\
& $(-0.291,-0.174)$ & $(-0.827,-0.500)$ \\
3 pass $/ \mathrm{m}^{2}$ & $-0.253^{* * *}$ & $-0.734^{* * *}$ \\
& $(-0.313,-0.192)$ & $(-0.919,-0.548)$ \\
4 pass $/ \mathrm{m}^{2}$ & $-0.281^{* * *}$ & $-0.768^{* * *}$ \\
& $(-0.347,-0.214)$ & $(-0.956,-0.580)$ \\
6 pass $/ \mathrm{m}^{2}$ & $-0.315^{* * *}$ & $-0.893^{* * *}$ \\
& $(-0.391,-0.239)$ & $(-1.114,-0.672)$ \\
\hline Constant & $0.980^{* * *}$ & $0.214^{* *}$ \\
& $(0.634,1.326)$ & $(0.041,0.387)$ \\
\hline$\rho$ & $0.557^{*}$ & $0.490^{*}$ \\
& $(0.428,0.678)$ & $(0.376,0.605)$ \\
\hline Log likelihood & -762.9 & -806.5 \\
Observations & 668 & 668 \\
\hline
\end{tabular}

Note: Confidence intervals in parentheses $*: p<0.10 ;{ }^{* *}: p<0.05$ ; ***: $p<0.01$. 


\section{References}

Alberini, A., B. Kanninen, And T. Cameron (1997): "Modeling Response Incentive Effects in Dichotomous Choice Contingent Valuation," Land Economics, 73, 309-324.

Arnott, R., A. De Palma, And R. Lindsey (1990): "The Economics of Bottleneck," Journal of Urban Economcics, 27, 111-130.

BASU, D. AND J. Hunt (2012): "Valuing of attributes influencing the attractiveness of suburban train service in Mumbai city: A stated preference approach," Transportation Research Part A, 46, 1465-1476.

Belenky, P. (2011): "Departmental Guidance on Valuation of Travel Time in Economic Analysis," US Department of Transportation.

Cameron, T. and J. Quiggin (1994): "Estimation Using Contingent Valuation Data from a "Dichotomous Choice with Follow-Up" Questionnaire," Journal of Environmental Economics and Management, 27, 218-234.

Cantwell, M., B. Caufield, And M. O’Mahony (2009): "Examining the Factors that Impact Public Transport Commuting Satisfaction," Journal of Public Transportation, 12, 1-22.

Commissariat Général À la Stratégie et à la Prospective (2013): L'évaluation socioéconomique des investissements publics, Commissariat Général à la Stratégie et à la Prospective, Goupe Présidé par E. Quinet, L. Baumstarck rapporteur.

Cox, T., J. Houdmont, And A. Griffiths (2006): "Rail passenger crowding, stress, health and safety in Britain," Transportation Research Part A: Policy and Practice, 40, 244-258.

CRCFRI (2012): "A literature review of passenger crowding on metropolitan railways: psychological, cultural human and economic factors," Project R2.104. 
D4E (2005): "Guide des bonnes pratiques pour la mise en oeuvre de la méthode des couts de transport," Série Méthode.

de Palma, A., M. Kilani, and S. Proost (2013): "Discomfort in mass transit and its application for scheduling and pricing," CES Discussion Paper Series.

Debrincat, L., J. Goldberg, H. Duchateau, E. Kroes, and M. Kouwenhowen (2006): "Valorisation de la régularité des radiales ferrées en Ile-de-France," Proceedings of the ATEC Congress, CD Rom edition.

dell'Olio, L., A. Ibeas, and P. Cecin (2011): "The Quality of Service desired by Public Transport Users," Transport Policy, 217-227.

Douglas, N. And G. Karpouzis (2006): "Estimating the passenger cost of train overcrowding," Paper presented at the 29th Australian Transport Research Forum.

Evans, G. And R. Wener (2007): "Crowding and personal space invasion on the train: Please don't make me sit in the middle," Journal of Environmental Psychology, 27, 90-94.

Feifei, Z. and J. Haicheng (2011): "A reinvestigation of crowding cost function form for public transit: linear or non-linear?" Paper presented at the ITEA Conference.

Flachaire, E. And G. Hollard (2007): "Starting-point bias and respondent uncertainty in dichotomous choice valuation surveys," Resource and Energy Economics, 29, 183-194.

HaAB, T. And K. MCConnel (2003): Valuing Environmental and Natural Resources: the Econometrics of Non-Market Valuation, Edward Elgar.

Hanemann, W., J. Loomis, And B. Kanninen (1991): "Statistical Efficiency of Double-Bounded Dichotomous Choice Contingent Valuation," American Journal of Agricultural Economics, 1255-1263. 
Haywood, L. And M. Koning (2012): "Avoir les coudes serrés dans le métro parisien : évaluation contingente du confort des déplacements," Revue d'Economie Industrielle, 111-144.

_ (2013): "Estimating crowding costs in public transport," DIW Berlin - Discussion papers.

Hensher, D. (2010): "Hypothetical bias, choice experiments and willingness to pay," Transportation Research Part B, 44, 735-752.

Hensher, D., J. Rose, And A. Collins (2011): "Identifying cmmuter preferences for existing modes and a proposed Metro in Sydney, Australia with special reference to crowding," Public Transport, 3, 109-147.

ITF-OECD (2014): "Valuing convenience in public transport," Technical report, chaired by M. Wardman.

JAnsson, J. (1979): "Marginal cost pricing of scheduled transport services," Journal of Transport Economics and Policy, 13, 268-294.

JARA-Diaz, S. And A. Gschwender (2003): "Towards a general microeconomic model for the operation of public transport," Transport Reviews, $4,453-469$.

Kato, H. (2014): "Valuation of urban rail service - Experiences from Tokyo, Japan," International Transport Forum - OCDE Discussion Paper.

Kato, H., Y. Kaneko, And M. Inoue (2010): "Comparative analysis of transit assignment: evidence from urban railway system in the Tokyo metropolitan area," Transportation, 37, 775-799.

Kilani, M., S. Proost, And S. VAn Der Loo (2014): "Road pricing and public transport pricing reform in Paris: Complements or subsitutes?" Economics of Transportation, 3, 175-187.

KopP, P. (2011): "The unpredicted rise of motorcycles: A cost benefit analysis," Transport Policy, 18, 613-622. 
Kraus, M. (1991): "Discomfort Externalities and Marginal Cost Transit Fares," Journal of Urban Economics, 29, 249-259.

Kraus, M. AND Y. Yoshida (2002): "The commuter's time-of-use decision and optimal pricing and service in urban mass transit," Journal of Urban Economics, 51, 170-195.

Kroes, E., M. Kouwenhouven, L. Debrincat, and N. Pauget (2013): "On the value of crowding in public transport for île-de-France," International Transport Forum - OCDE Discussion Paper.

Leurent, F., V. Breteau, And N. Wagner (2009): Cout marginal social de la congestion routiere. Actualisation et critique de l'approche Hautreux, LVMT, Rapport pour le compte du MEDDAT.

Leurent, F. And K. Liu (2009): "On Seat Congestion, Passenger Comfort and Route Choice in Urban Transit: a Network Equilibrium Assignment Model with Application to Paris," Paper Presented at the Annual Congress of Transportation Research Board, 09 - 1784.

LI, Y. (2003): "Evaluating the Urban Commute Experience: A Time Perception Approach," Journal of Public Transportation, 6, 41-67.

Li, Z. And D. Hensher (2011): "Crowding and public transport: a review of willingness to pay evidence and its relevance in project appraisal," Transport Policy, 880-887.

LiNDSEY, R. (2006): "Do economists reach a conclusion on road pricing?" Econ Journal Watch, 3, 292-379.

Litman, T. (2008): "Valuing Transit Service Quality Improvements," Journal of Public Transportation, 11, 43-64.

Lu, H., A. Fowkes, And M. Wardman (2008): "Amending the incentive for strategic bias in stated preference studies: Case study in users' valuation of rolling-stock," Transportation Research Record - Journal of the Transportation Research Board, 2049, 128-135. 
Malibach, M., C. Schreyer, H. Van Hessen, C. Doll, and B. PAWlowsKa (2008): Handbook on estimation of external costs in the transport sector, CE Delft, The Netherlands.

Ministère Des Droits Des femmes (2012): Chiffres-clés 2011 de l'égalité entre les femmes et les hommes, Ministère des droits des femmes.

Mitchell, R. And R. Carson (1989): Using Surveys to Value Public Goods: The Contingent Valuation Method, Washington, D.C.: Resources for the Future/Johns Hopkins University Press.

Mohd Mahudin, N., T. Cox, And A. Griffiths (2012): "The measurement of rail passenger crowding: scale development and psychometric properties," Transportation Research Part F, 15, 38-51.

Mohring, H. (1972): "Optimization and Scale Economies in Urban Bus Transportation," American Economic Review, 62, 591-604.

Newman, P. And J. Kenworthy (1989): Cities and Automobile Dependance. An International Sourcebook, Gower Technical, Sidney.

Observatoire de la mobilité de la ville de Paris (2000): "Bilan des Déplacements de la Ville de Paris," Disponible sur le site internet de la ville de Paris.

___ (2007): "Bilan des Déplacements de la Ville de Paris," Disponible sur le site internet de la ville de Paris.

__ (2009): "Bilan des Déplacements de la Ville de Paris," Disponible sur le site internet de la ville de Paris.

OMNIL (2013): Enquête globale transport : les déplacements en transports collectifs, Syndicat des Transports de la région Ile-de-France.

ORSTIF (2010): "Enquête auprès des salariés d'Ile-de-France sur les transports en commun domicile-travail," Mimeo. 
Parry, I., W. Harrington, and M. Walls (2007): "Automobile Externalities and Policies," Journal of Economic Literature, 65, 373-399.

Parry, I. And K. Small (2009): "Should Urban Transit Subsidies Be Reduced?" American Economic Review, 99, 700-724.

Pel, A., N. Bel, And M. Pieters (2014): 'Including passengers' response to crowding in the Dutch national train passenger assignment model," Transportation Research Part A, 66, 111-126.

Proost, S. And K. Dender (2008): "Optimal urban transport pricing in the presence of congestion, economies of density and costly public funds," Transportation Research-Part A, 42, 1220-1230.

Prud'homme, R., M. Koning, L. Lenormand, and A. Fehr (2012): "Public Transport Congestion Costs: The Case of Paris Subway," Transport Policy, 21, 101-109.

Prud'homme, R. And P. Kopp (2008): "Worse than a Congestion Charge: Paris Traffic Restrain Policy," in Road Congestion Pricing Book, ed. by R. Richardson and C. Chang Hee, Edward Elgar, 252-272.

Raveau, S., J. Munoz, and L. De Grange (2011): "A topological route choice model for metro," Transportation Research Part A, 45, 138-147.

Régie Autonome des Transports Parisiens, . (2011): "Automatiser la ligne 1 : un défi technique, organisationnel et social," Rapport d'activité du groupe Ratp.

Samuelson, P. (1954): "The pure theory of public expenditure," The Review of Economics and Statistics, 36, 387-389.

Small, K. And E. Verhoef (2007): The Economics of Urban Transportation - 2d Edition, Routledge.

Syndicat des Transports de la Région Ile-De-France (2009): Les transports en communs en chiffres 2000-2009, OMNIL. 
Szolnoki, G. And D. Hoffman (2013): "Online, face-to-face and telephone surveys- Comparing different sampling methods in wine consumer research," Wine Economics and Policy, 2, 57-66.

Technologia (2010): "Etude d'impact des transports en commun de Région Parisienne sur la santé des salariés et des entreprises," Mimeo.

Tirachini, A., D. Hensher, And S. Jara-Diaz (2010): "Comparing operator and users costs of light rail, heavy rail and bus rapid transit over a radial public transport network," Research in Transportation Economics, $29,231-242$.

Tirachini, A., D. Hensher, And J. Rose (2013): "Crowding in public transport systems: Effects on users operation and implication for the estimation of demand," Transportation Research Part A, 53, 36-52.

_ (2014): "Multimodal pricing and optimal design of urban public transport: the interplay between traffic congestion and bus crowding," Transportation Research Part B, 61, 33-54.

Tsekeris, T. And S. Voss (2009): "Design and Evaluation of Road Pricing: State-of-the-art and Methodological Advances," Netnomics, 5-52.

UITP (2014): Statistics brief - World metro figures, UITP.

Wardman, M. (2001): "A Review of British Evidence on Time and Service Quality Valuations," Transportation Research E, 37, 107-128.

Wardman, M. And G. Whelan (2011): "Twenty years of rail crowding valuation studies: evidence and lessons from british experience," Transport Reviews, 31, 379-398.

Wener, R., G. Evans, And P. Boately (2005): "Commuting stress: Psychological effects of a trip and spillover into the workplace," Transportation Research Board, 1924/2005, 112-117. 
Whelan, G. And J. Crockett (2009): "An investigation of the willingness to pay to reduce rail overcrowding," Proceeding of the First International Conference on Choice Modelling, Harrogate, England. 